\title{
LA RESTAURACIÓN DE LA CAPILLA DEL SANTÍSIMO DE LA IGLESIA DE SANT MIQUEL DE CARDONA
}

\author{
BARCELONA/ESPAÑA
}

\author{
(THE RESTORATION OF THE CHAPEL OF THE SANTISIMO OF THE CHURCH OF \\ SANT MIQUEL DE CARDONA/BARCELONA/SPAIN)
}

Antoni González Moreno-Navarro, Arquitecto

Jefe del Servicio del Patrimonio Arquitectónico

$128 \cdot 42$ de la Diputación de Barcelona

Fecha de recepción: 27-111-92

\section{RESUMEN}

La pequeña capilla de planta de cruz y cúpula sobre el crucero, que tomó su forma actual en 1744, llegó a nosotros en pésimas condiciones formales y de uso. Enfocada su restauración como una "resignificación", un objetivo fundamental fue darle una imagen atractiva, nueva, que pudiera despertar el interés entre sus usuarios, inmersos en una transitoria "anhedonia monumental". La actuación debia dar respuesta también a los conflictos de carácter conceptual y simbólico entre el esquema tradicional de una capilla reservada al Santisimo y la nueva mentalidad que generó la reforma litúrgica del concilio Vaticano II.

\section{SUMMARY}

The little chapel with the cross-shaped ground plan and the dome over the transept, which was finished in 1744, reached our day in very bad conditions both formal and practical. Its restoration was approached as a "change of meaning", the basic objective was to give it an attractive new appearance which could awake interest among its visitors immersed in a transitory "monumental anhedonia". The performance was also supposed to solve the conflicts of conceptual and symbolic character between a traditional scheme of a chapel reserved for the Santisimo and the new mentality which generated the liturgical reform of the Second Vatican Council.
Los seis o siete mil habitantes de la ducal villa de Cardona, en el centro geográfico de Cataluña, viven con cierta preocupación un final de milenio que no anuncia buenos augurios para la ya milenaria ciudad. La situación económica y social es ciertamente preocupante. Las afamadas minas de potasas - motor de la economia local desde la colonización romana-, han sido cerradas por falta de rentabilidad, sin que aún se hayan encontrado soluciones alternativas efectivas.

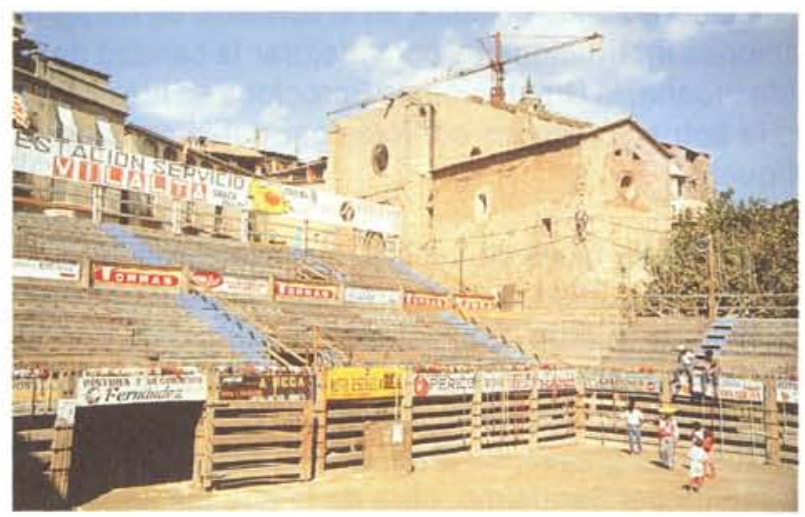

Fig. 1. - La iglesia de Sant Miquel y la plaza de toros de Cardona.
Uno de los caminos ensayados para la reactivación es el fomento y aprovechamiento de los recursos que puedan generar turismo, que en Cardona no son pocos. En primer lugar, el patrimonio arquitectónico: el viejo castillo ducal - que cobija el parador nacional-, la colegiata de Sant Vicenç - el mejor ejemplo conservado de arquitectura religiosa románica de Cataluña-, los restos del recinto amurallado, el casco antiguo - hace poco declarado conjunto monumental-, presidido por la iglesia parroquial de Sant Miquel.

También la famosa montaña de sal, que bien explotada puede constituir un conjunto paisajistico lúdico, cultural y turístico de máximo interés, y el famoso " $\mathrm{co}$ rre de bou", la capea o fiesta taurina popular (bien arraigada entre la población a pesar de la persecución gubernamental que sufre), en la que los cardonenses desafían al animal colgados de recias cuerdas atadas a la talanquera de la plaza de toros, una bella plaza (estable, aunque desmontable) que se monta cada año entre el ayuntamiento y la iglesia, cuya fábrica emer. ge por detrás de los tendidos de sol (Fig. 1). En esa iglesia de Sant Miquel se halla precisamente la capilla del Santísimo cuya restauración narramos aquí. 


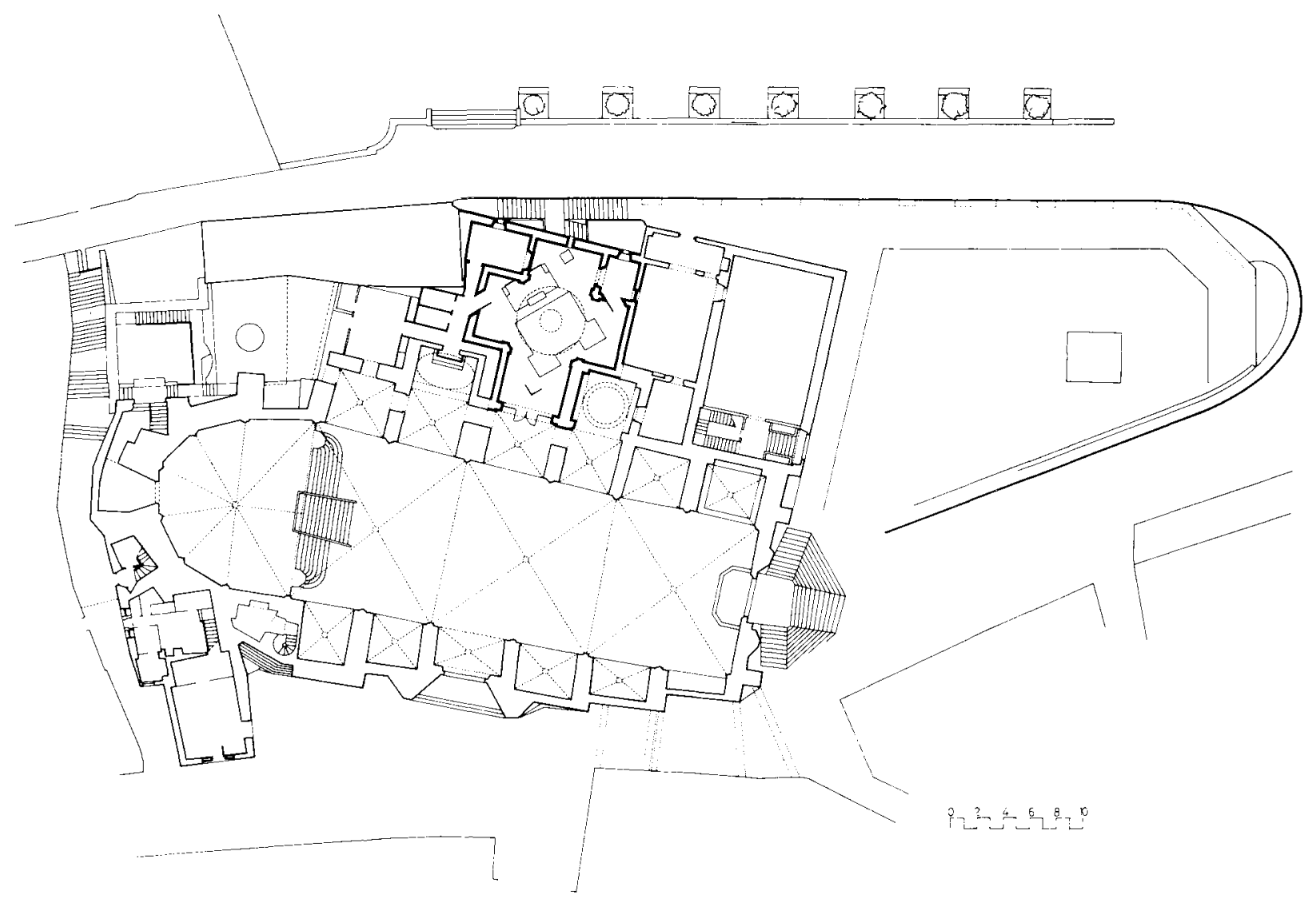

Fig. 2. - Planta general de la iglesia de Sant Miquel de Cardona.

\section{La iglesia de Sant Miquel}

El conjunto parroquial de Sant Miquel está formado por la iglesia y una serie de edificios adosados: la rectoria, el recinto del antiguo cementerio y algunas capillas de volumetría exenta. Se halla entre las plazas del Mercado y de la Fira, espacios urbanos que actúan como centros comerciales, lúdicos y administrativos de la villa.

El templo, consagrado en 1398, es una construcción gótica, levantada entre los siglos XIII y XIV en el lugar que ocupó la iglesia románica documentada desde el 1013. Es de nave única con capillas entre contrafuertes, ábside heptagonal y cubierta sobre tres bóvedas ojivales (Fig. 2). En campanario tiene un piso del siglo $\mathrm{XI}$, otro del XII con dos niveles de ajimeces, y está coronado por un cuerpo del siglo XIX y una estructura metálica colocada en 1989.

Las primeras reformas importantes del templo gótico datan del primer cuarto del siglo XVI: la nueva sacris- tía, la cripta bajo el altar mayor, y la ampliación de las capillas de mediodia, entre ellas la de Sant Domènec, hoy dedicada al Santísimo. Al inicio de la última guerra civil, la iglesia sufrió graves daños, especialmente el interior (el magnífico retablo mayor barroco fue destruido) y en 1940, acabada la guerra, se realizó una primera restauración.

A mediados de los ochenta, en el contexto de las aportaciones institucionales para mejorar la calidad de la vida urbana, la Diputación de Barcelona se hizo cargo de la actuación en los edificios parroquiales de Sant Miquel.

Las primeras fases de la obra, que afectaron al campanario, las cubiertas y la nueva sacristía, duraron hasta 1990, y fueron proyectadas y dirigidas por el arquitecto Albert Bastardas, con la colaboración de Xavier Guitart. Una vez solventados los problemas estructurales más graves, se programó la recuperación de la capilla del Santísimo, obra de la que me encargué personalmente a petición de la junta parroquial. 


\section{La antigua capilla de Sant Domènec}

De la primera ampliación de la capilla de Sant Domènec (1606-1634) sólo nos ha quedado el arco renacentista de acceso, abierto en el muro gótico. En 1744, una nueva ampliación dió a la capilla la actual planta de cruz, colocándose tres altares. El nuevo espacio se cubrió con bóvedas, levantándose sobre el crucero una cúpula tradicional, apoyada sobre pechinas, y coronada con linterna. También la decoración fue la acostum. brada en la versión vulgar del lenguaje barroco: moldurajes bocelados, relieves vegetales y geométricos, y figuras de escasa fortuna artística (mofletudos angelitos, tetudas cariatides mancas y párvulos orantes de ridicula cabezuela y enormes manos, Fig. 3).

Los hechos revolucionarios de 1936 también afectaron a la capilla, ya entonces conocida como del Santísimo. Después de la guerra, por tanto, hubo de ser de nuevo engalanada y se hizo con los recursos y el gusto de la época, tanto unos como otro más bien escasos. Los muros se cubrieron de elementos iconográficos eucarísticos y de la vida de Jesucristo y un alto zócalo de madera pintada, mientras pilastras y arcos se decoraron con motivos geométricos. Se colocó un nuevo altar de mármol y, sobre él, un retablo con hornacina y una vidriera eucarística.

Con el tiempo, la decoración se enriqueció con horrendas lámparas de tubos fluorescentes (Fig. 4), mientras el agua filtrada a través de la cubierta en mal estado, el humo de las velas, y el uso cotidiano hicieron que la capilla llegara a tener un aspecto deplorable. Asi estaban las cosas cuando la Junta parroquial y el párroco la pusieron en nuestras manos. $Y$ como el juramento hipocrático del restaurador no permite abandonar un monumento enfermo por feo y pequeño que sea (Fig. 5), aceptamos gustosos el reto de sanar en lo posible la capilla.

El diagnóstico, la prescripción y la terapia respecto de las patologias orgánicas - prácticamente una, la humedad-, fueron resueltos en las fases anteriores a nuestra intervención, cuando se rehicieron todas las cubiertas del conjunto parroquial (Fig. 6). Y resueltas las patologías somáticas, nos cupo ocuparnos de las patologías psiquicas -es decir, las de la psique, el alma- del elemento arquitectónico.

Una vez más podiamos acometer una restauración como resignificación de una arquitectura histórica. De nuevo, la restauración física podia catalizar el reencuentro entre la arquitectura preexistente y sus usuarios, inmersos en una transitoria anhedonia monumental, que en el caso de la capilla de Cardona tenia una doble causa, la dificultad del uso y lo desmotivador de una imagen caduca. Los dos aspectos - uso e imagen - de los que debia partir su resignificación. Con este doble objetivo, iniciamos los estudios previos a la restauración.

(c) Consejo Superior de Investigaciones Científicas Licencia Creative Commons 3.0 España (by-nc)

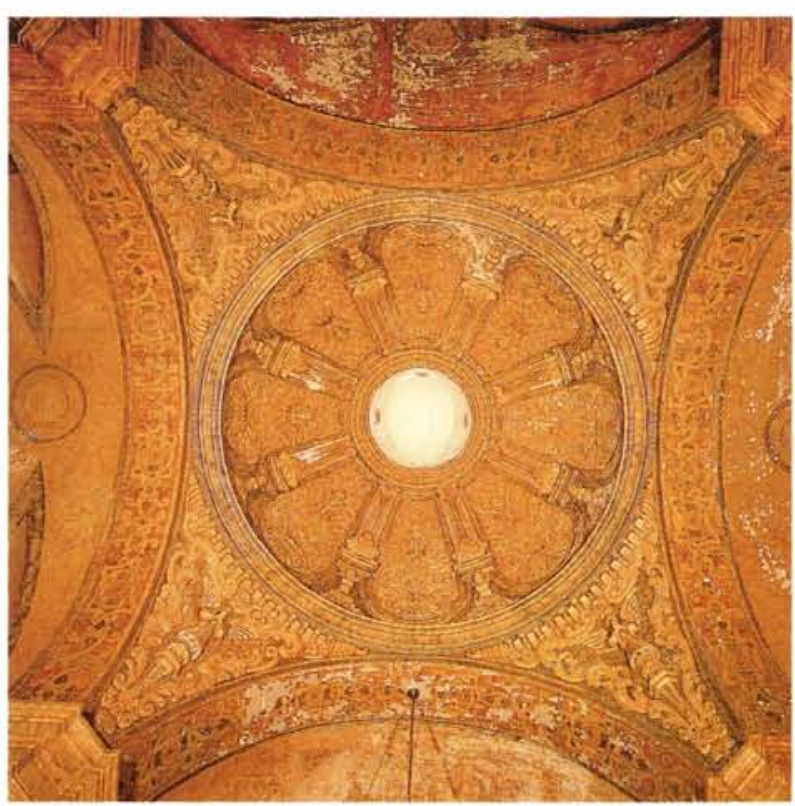

Fig. 3. - La cúpula del crucero de la capilla del Santisimo, antes de la restauración.

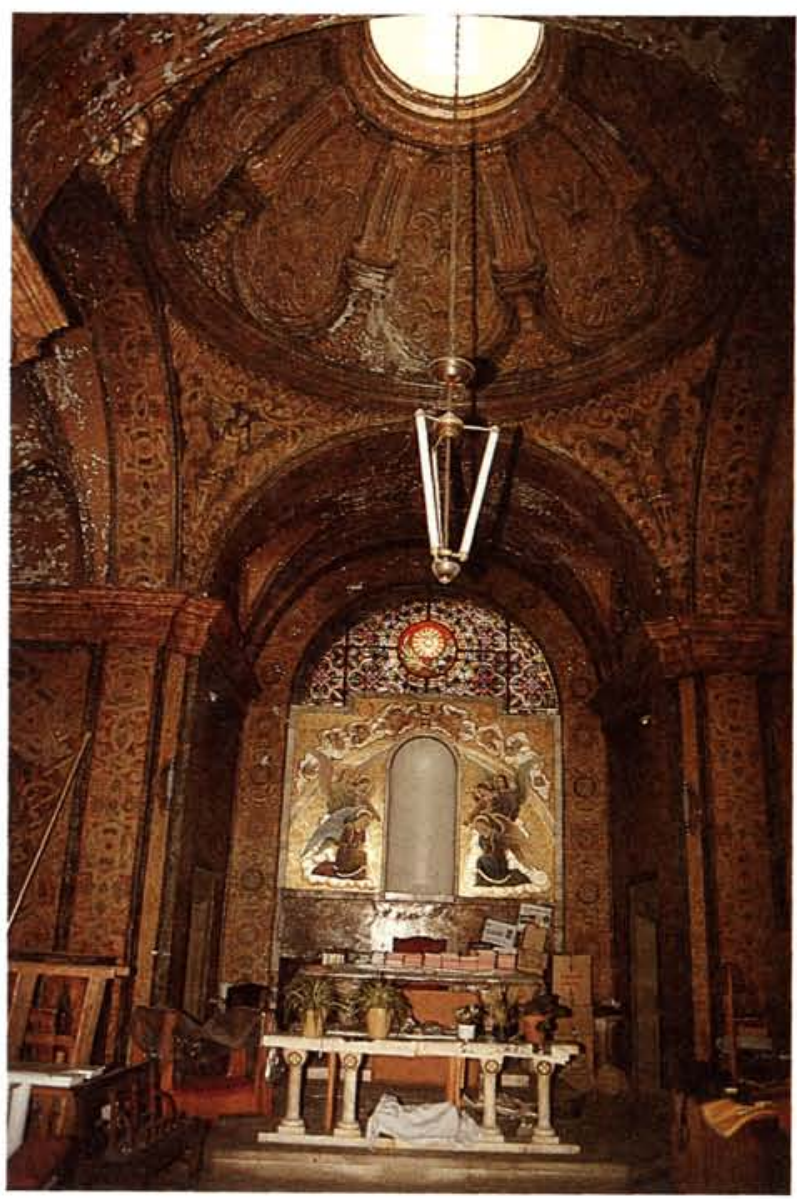

Fig. 4. - Estado del interior de la capilla antes de la restauración. http://informesdelaconstruccion.revistas.csic.es 


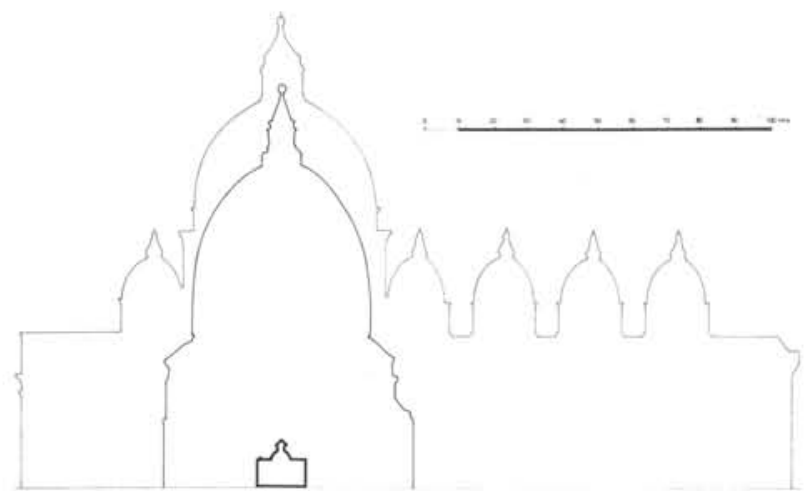

Fig. 5. - Comparación de las dimensiones de las cúpulas de San Pe. dro del Vaticano, Santa María de las Flores de Florencia y la capilla del Santisimo de Cardona.

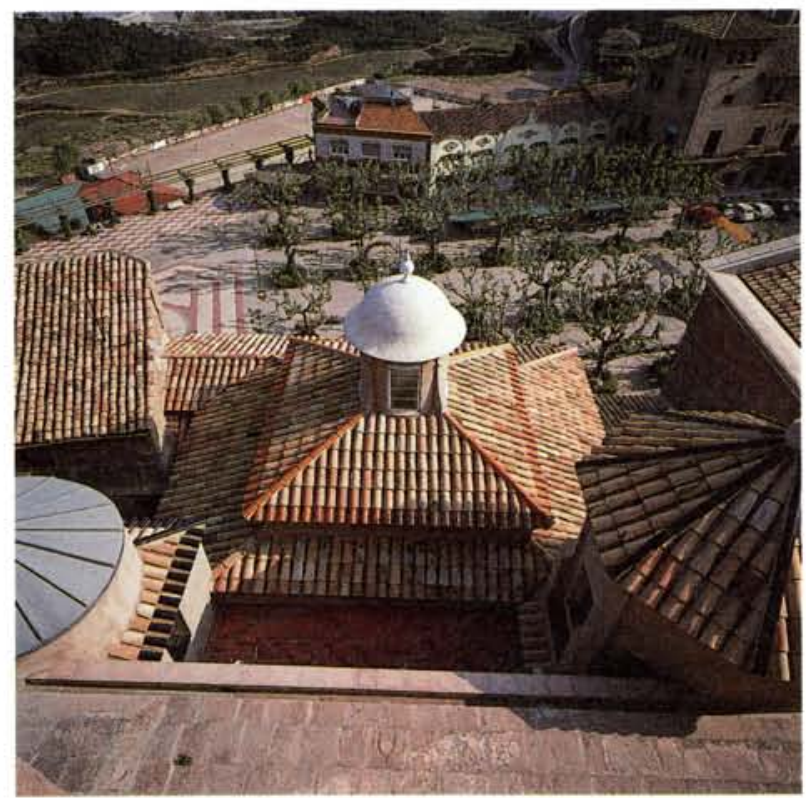

Fig. 6. - Las cubiertas del conjunto parroquial, restauradas. En el centro, la de la capilla del Santísimo.

\section{Un nuevo esquema de planta}

En cuanto a cómo utilizar el espacio habia que tener en cuenta su doble función. Como ocurre en tantas capillas del Santísimo, la de Cardona asume dos funciones: ser espacio dedicado a la reserva eucarística (lugar de oración, de recogimiento, de "visita"), y recinto de celebración de la misa cuando el número reducido de fieles no hace aconsejable utilizar la nave principal del templo. Esta dualidad, que desde un punto de vista funcional no supone un grave problema, sí tiene una problemática litúrgica, al menos en el terreno conceptual y, en nuestro caso, en el simbólico.

En el esquema tradicional de uso de la capilla, los bancos de los fieles se situaban a lo largo de la nave mayor, en cuya cabecera el retablo mayor contenia la mesa y, en lo alto, el sagrario o tabernáculo (Fig. 7). Es decir, la reserva eucarística presidia la celebración de la misa. En la restauración de los años cuarenta, se mantuvo este esquema lineal, que no cambió tampoco cuando el altar se adelantó para permitir que el celebrante mirara a los fieles, de acuerdo con la letra del Concilio Vaticano II. Altar y sagrario continuaron superpuestos en el eje longitudinal de la nave (Fig. 8).

Pero atendiendo no sólo a la normativa litúrgica que generó el Concilio, sino a la nueva mentalidad que subyacía en ella, ya no parecía correcto que la reserva eucarística presidiera la celebración comunitaria de la misa, un acto mucho más significativo desde el punto de vista litúrgico. Incluso ya no parecía lógico (o por lo menos dejaba de ser imprescindible) que en nuestras iglesias se segregara una capilla para el Santísimo, como se venía haciendo desde unos siglos antes.

Fiel a esa nueva mentalidad, que entraba en conflicto con el uso tradicional de nuestra capilla, el nuevo párroco, si bien nunca nos habló de prescindir del uso como capilla del Santísimo (ya que los fieles no lo hubieran aceptado), nos planteó la necesidad de mejorar la posición relativa entre el sagrario y el altar, aspecto que habia de resultar decisivo en el proyecto de restauración.

Otro aspecto derivado de la nueva mentalidad conciliar que tuvimos en cuenta, fue la posición relativa entre el propio altar y la asamblea de fieles. Para patentizar la participación de éstos en la celebración no parece suficiente el hecho de que el oficiante les dé la cara, sino que conviene que la asamblea rodee el altar. Eso es lo que habiamos hecho ya en la restauración de otras iglesias, como en la de Sant Vicenç de Malla (Ver Informes, n. 397, pág. 36).

En la capilla de Cardona, sin embargo, este esquema no acababa de funcionar. Al disponer los bancos en forma de $\mathrm{C}$ se reducia la capacidad, los fieles quedahttp://informesdelaconstruccion.revistas.csic.es 


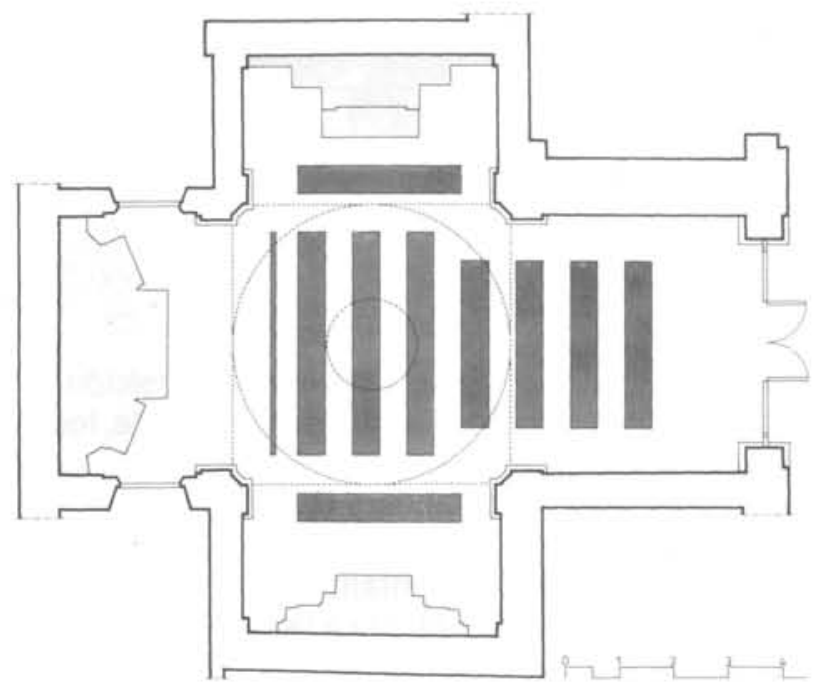

Fig. 7.-Esquema tradicional de utilización de la capilla desde el siglo XVIII.

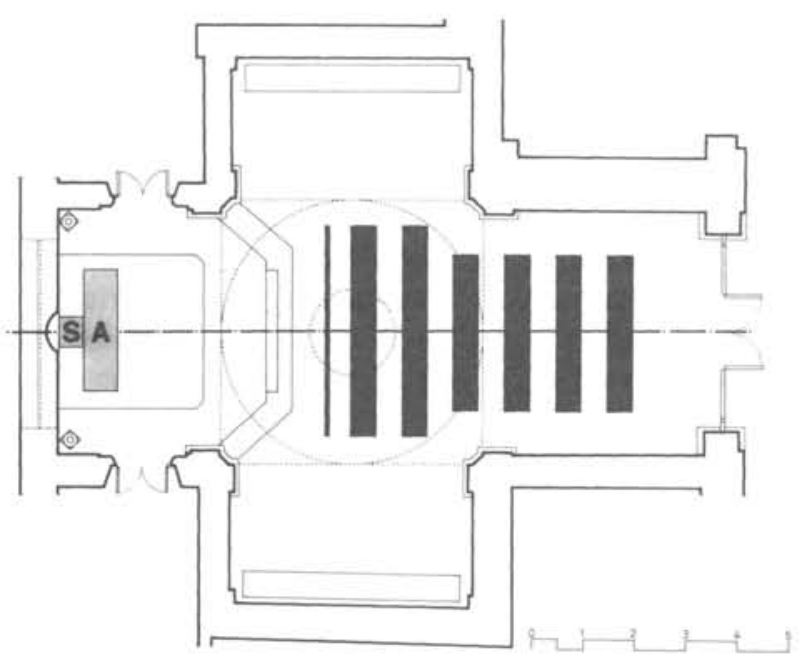

Fig. 8. - Esquema de funcionamiento después de la restauración de 1940.

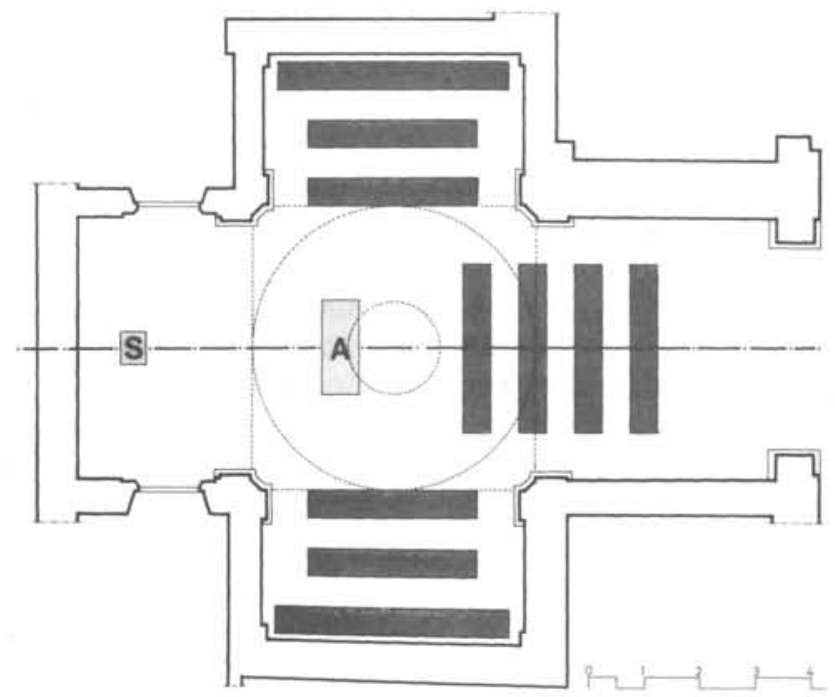

Fig. 9. - Esquema en cruz con el sagrario (S) y el altar (A) en el mismo eje, que se rehuso.

(c) Consejo Superior de Investigaciones Científicas Licencia Creative Commons 3.0 España (by-nc) ban encarados a poca distancia, y el espacio situado bajo la linterna, el mejor iluminado, quedaba como terreno de nadie (Fig. 9). Era evidente que el reducido tamaño de la capilla invalidaba un esquema funcional que, teóricamente, encajaba bien en la planta de cruz. Por otra parte, con este esquema tampoco solucionábamos el problema principal, el de la superposición del sagrario y el altar.

\section{Proyectar es recordar}

Buscando soluciones, como proyectar es imaginar, e imaginar es recordar, vino a la memoria una capilla singular de nuestra arquitectura religiosa, la que proyectó en 1753 Ventura Rodríguez para la Virgen del Pilar en su basílica de Zaragoza (Fig. 10). Esta sugestiva capilla, en realidad un baldaquino bajo las altas bóvedas de la basílica, tenía un aspecto que era especialmente útil para nosotros. En ella, la Virgen del Pilar es la indiscutible protagonista y su presencia inunda la atmósfera de aquel espacio. Pero la Virgen no ocupa el lugar preeminente, el altar mayor, que -en buena lógica litúrgica - debe reservarse para oficiar la misa. Ventura Rodriguez había resuelto la antinomia desplazando ligeramente a la Virgen del eje principal, pero situándola en otro eje virtual de la planta elipsoidal de la capilla; un desdoblamiento de ejes que permite que tanto el altar mayor como el de la Virgen co-presidan el espacio, sin llegar a saberse cuál de los dos es el desplazado, aspecto que debe ser resuelto subjetivamente por el espectador (Fig. 11).

En la capilla de Cardona, como su espacio - por es. tar definido en gran manera por la cúpula- no tiene una dirección dominante, un desdoblamiento de ejes podia también resolver nuestros problemas. Así, girando entre si los ejes del sagrario y del altar siguiendo el círculo proyectado por la cúpula, surgió el nuevo es. quema (Fig. 12). En la decisión sobre qué elemento debia abonadonar su situación anterior, influyeron dos hechos, uno simbólico y otro funcional. La tradicional utilización como capilla del Santísimo, sugeria que el tabernáculo siguiera en su lugar. Por otra parte, si no moviamos el altar, la relación con la asamblea de fieles continuaria siendo la misma.

Situando el altar y la asamblea en un eje diagonal, conseguiamos resolver los dos aspectos, el simbólico y el funcional. El primero, porque si bien el sagrario ocupa una posición lateral respecto del altar - como recomienda el Concilio-, al permanecer en su lugar, no parece desplazado, y nadie puede responsabilizar a la liturgia conciliar de un aparente arrinconamiento del Santísimo. El aspecto funcional quedaba resuelto también, ya que la asamblea, si bien no rodeaba al altar, se acercaba a él y, además, ocupaba el espacio central bien iluminado. 


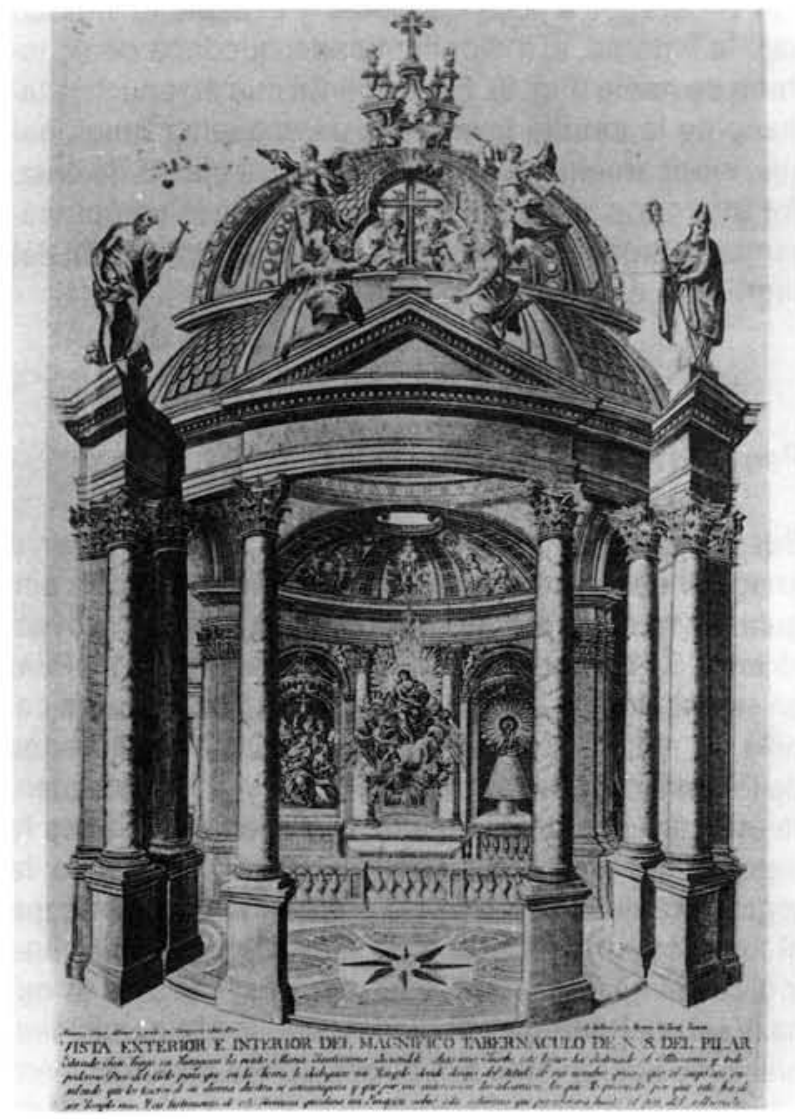

Fig. 10. - Capilla de la Virgen del Pilar en su basilica de Zaragoza.

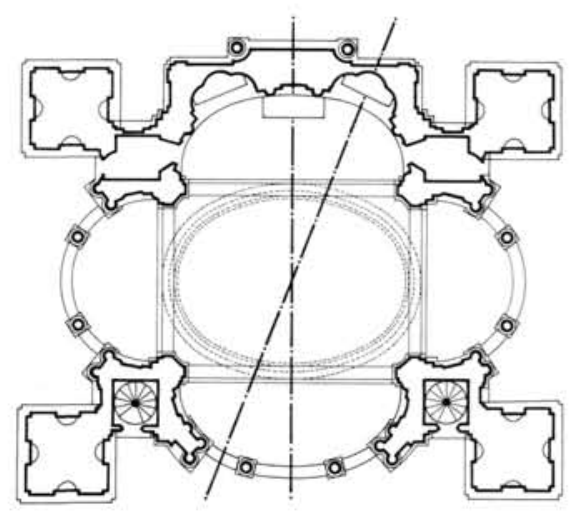

Fig. 11. - Planta de la capilla del Pilar con los dos ejes, el del altar mayor y el de la Virgen.

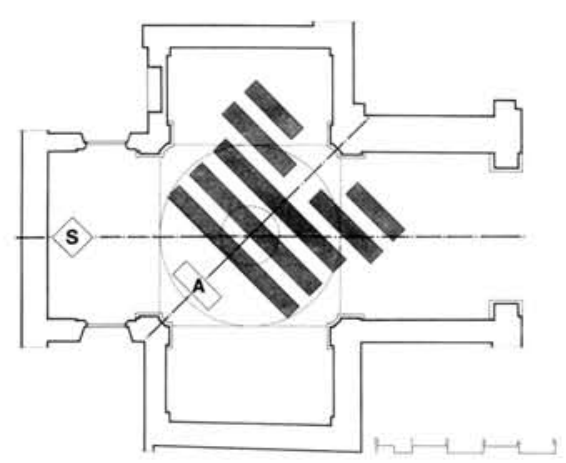

Fig. 12. - Esquema de funcionamiento de la capilla del Santísimo de Cardona, desdoblando los ejes del sagrario (S) y del altar (A). (C) Consejo Superior de Investigaciones Científicas Licencia Creative Commons 3.0 España (by-nc)
Para reforzar el giro de ejes y la nueva disposición del espacio litúrgico dentro del gálibo preexistente, todos los elementos (la tarima del presbiterio, el altar, las banquetas de los celebrantes y el atril, el conjunto de bancos de los fieles, la base de la peana del sagrario y las mamparas: las que enfatizan el presbiterio, las que privan de vistas la entrada a la sacristía y el confesionario) se situaron siguiendo el orden pautado por el nuevo pavimento, que con ese fin toma una directriz perpendicular al nuevo eje litúrgico y que asoma al exterior de la capilla como invitando a entrar en ella (Fig. 13).

\section{Una visita a la capilla}

Situada frente a la actual puerta principal de la iglesia, la luz que rebosa de la capilla es la primera que ve el visitante (Fig. 14), que al aproximarse será recibido por el pavimento, mientras la lámina de vidrio gra. bada al ácido le impedirá participar plenamente del espacio interior, aunque le permita intuirlo (Figs. 15 y 16). Tras la puerta, un elemento vertical, no reconocible, evita la sensación de desorden que el giro de los bancos pueda producir. Y emergiendo de ese elemento, el eje de luz parece enlazar algún objeto oculto con la linterna aún no visible.

Abierta la doble puerta de vidrio (Fig. 17), el obstáculo tomará cuerpo: una mampara en forma de $V$ que en el interior juega un papel importante en la delimitación del nuevo espacio litúrgico y, respecto del exterior, permite algo tradicional en nuestra arquitectura, el descubrimiento secuencial del espacio (Fig. 17b), un tránsito que en nuestro caso era esencial para que el espectador percibiera el cambio de eje sin sobresalto ni desorientación.

Cuando el visitante entre en la capilla y rebase la mampara (Fig. 18), descubrirá en primer lugar el destino final de la luz que rasga el muro: el tabernáculo, destinatario durante tantos años de aquel lugar (Figs. 19 y 19b). Pero inmediatamente, el espectador apreciará que algo ha pasado en aquel espacio. La inclina. ción de los bancos, el eje que atraviesa suspendido, $y$, sobre todo, el nuevo punto de vista que toma por el sesgo que le ha obligado a hacer la mampara, le harán descubrir inmediatamente el nuevo eje principal, el del espacio litúrgico de la celebración eucarística, presidido por la cruz y el altar (Fig. 20).

http://informesdelaconstruccion.revistas.csic.es 


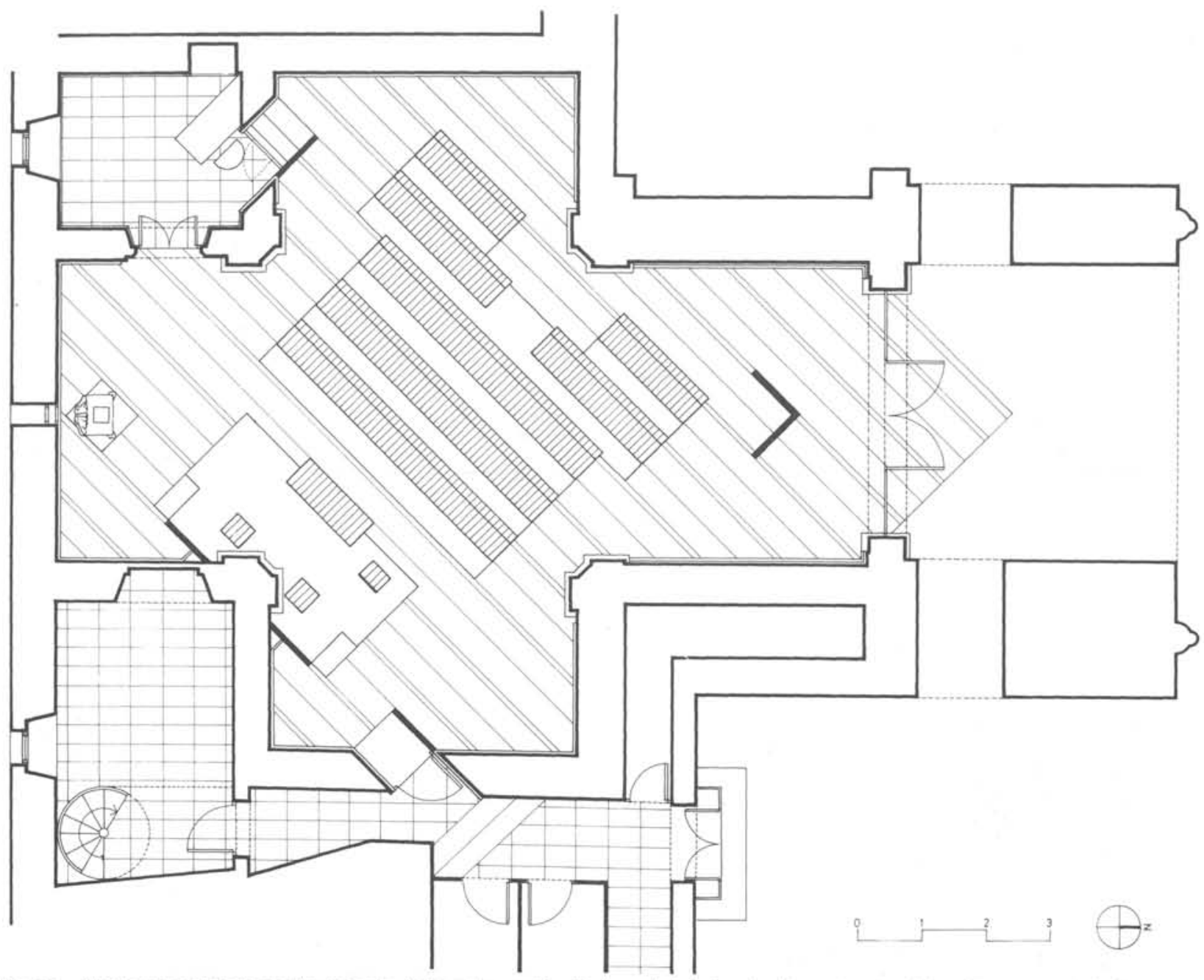

Fig. 13. - Planta general de la capilla después de la restauración. En la parte inferior, las dependencras del archivo parroquial y la cone. xión con la sacristia. En la parte superior, a la izquierda, el espacio penitencial con el confesionario-despacho.

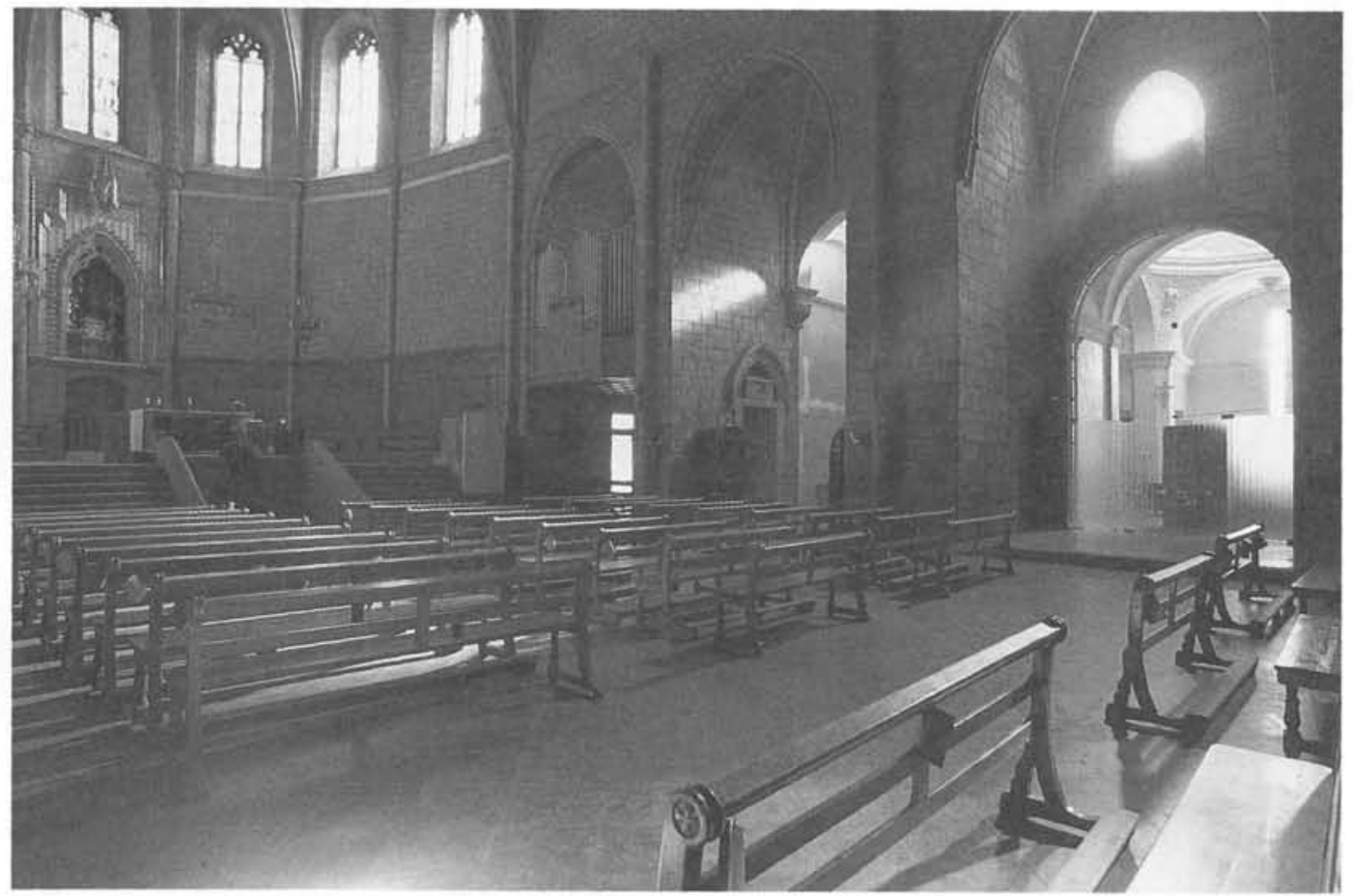

Fig. 14. - La capilla, abierta a la nave del templo. 


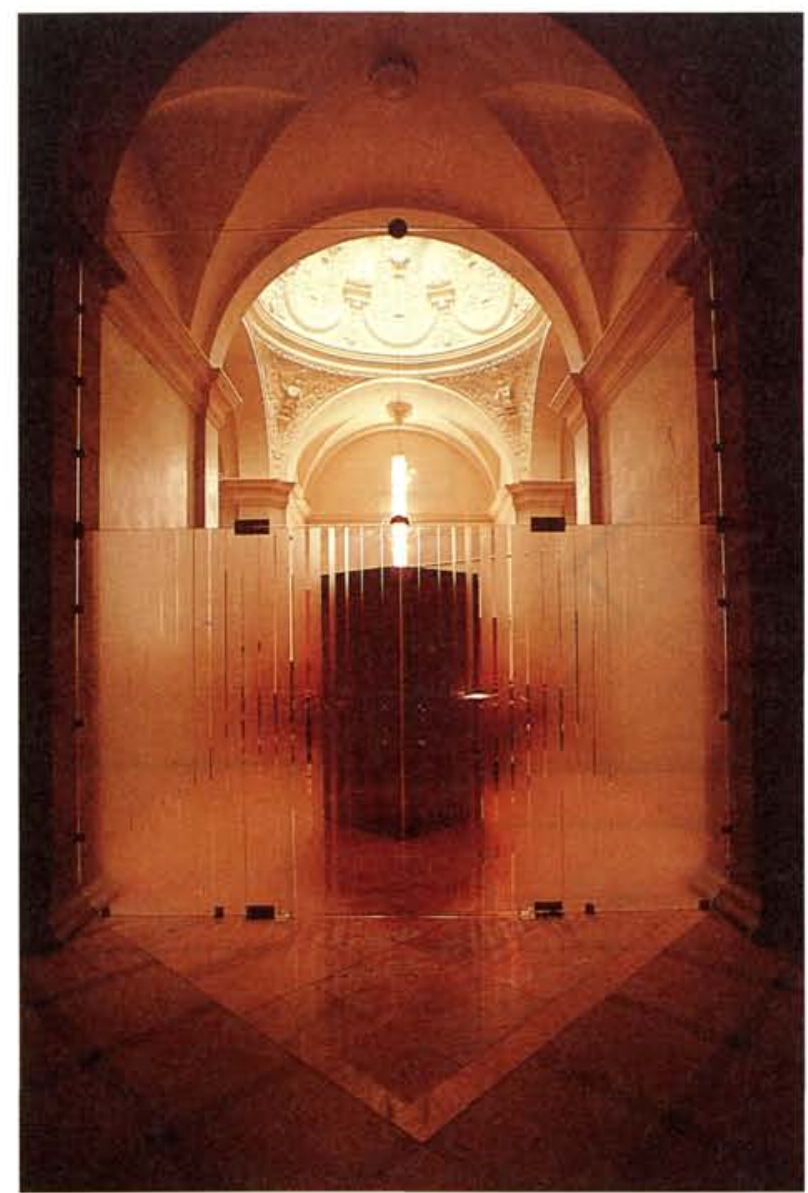

Fig. 15. - Vista de la capilla desde la nave.

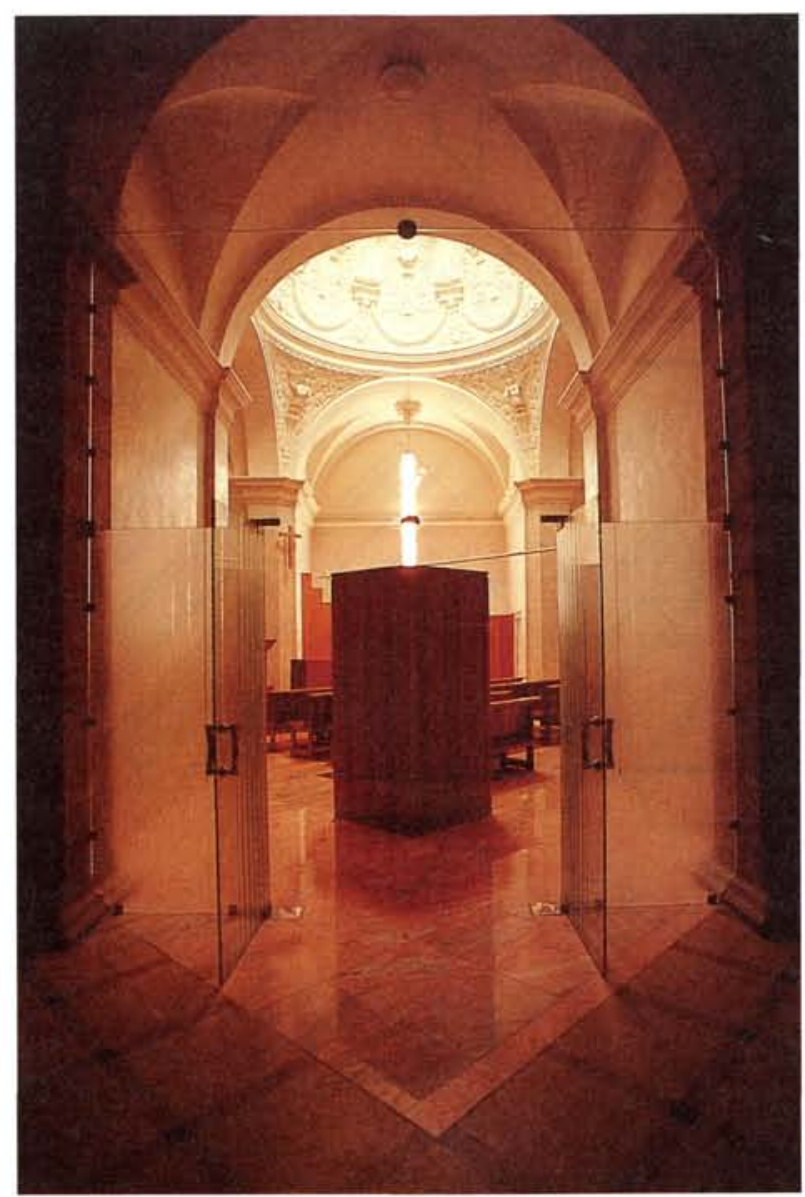

Fig. 17. - Vista desde la nave. En primer término, la mampara que obli ga al descubrimiento secuencial del espacio interior.

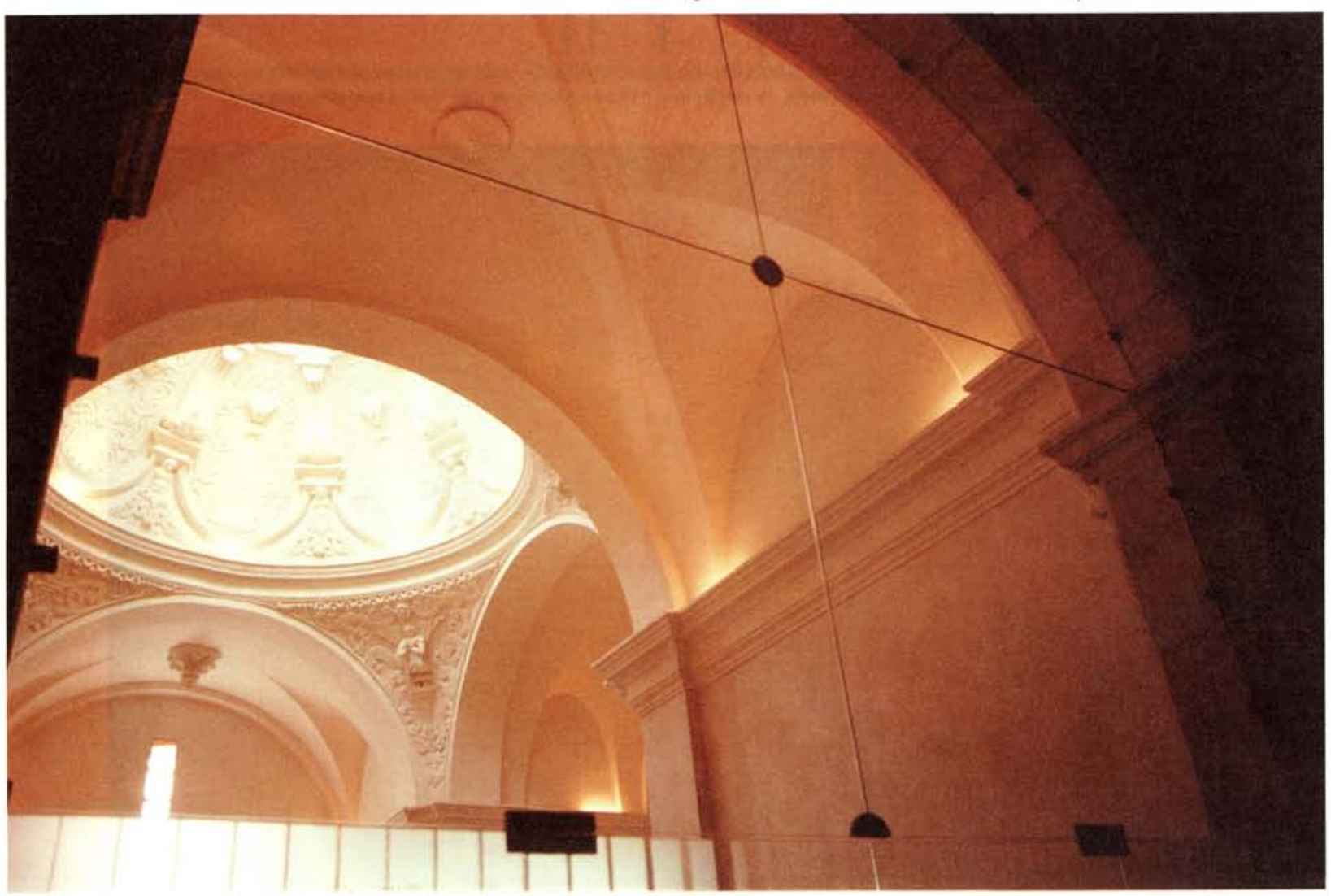

Fig. 16. - Vista de la cúpula del crucero desde el exterior de la capilla.

(c) Consejo Superior de Investigaciones Científicas Licencia Creative Commons 3.0 España (by-nc) 


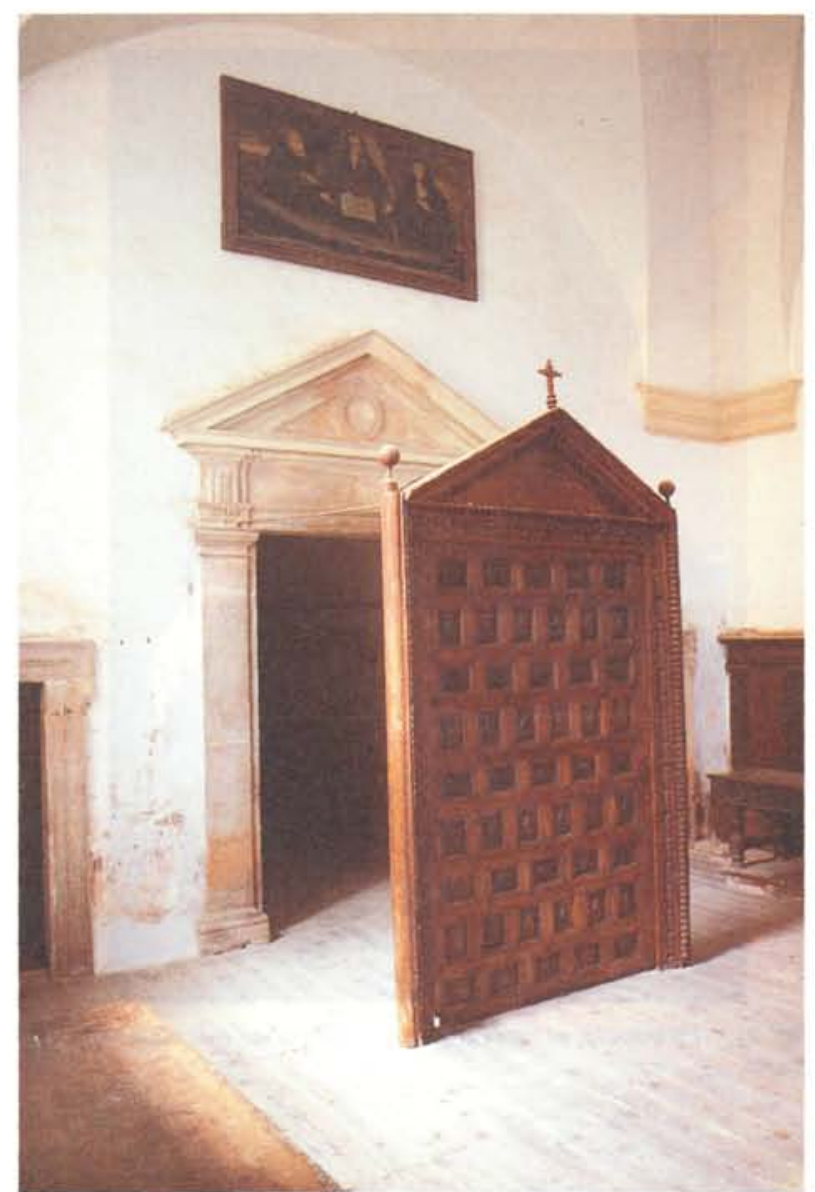

Fig. 17b. - Mampara en San Millán de la Cogolla (La Rioja), en la que se inspira la de la capilla del Santísimo.

En la justificación del nuevo orden interior de la capilla ya ha quedado expuesto que, en el desplazamiento relativo entre el altar y el sagrario, era éste, por respeto a la tradición, el que debía mantener su posición. Sin embargo, ese privilegio no era suficiente. La importancia que iban a cobrar los elementos orientados en el eje diagonal, podia acabar por marginar al Santísimo. Pareció evidente, pues, la necesidad de un gesto potente que reclamara para él la atención que merecia.

Surgió asi la idea de que un haz de luz, partiendo en apariencia de la linterna, descendiera hasta el tabernáculo, rasgando para ello el muro de mediodia (Fig. 21). Y como el realzamiento formal de la significación del Santísimo quedaba confiado a esa rasgadura y a la peana que debia sostener el sagrario, decidimos concentrar en esos dos elementos toda la riqueza decorativa que nuestra actuación iba a aportar a la capi-

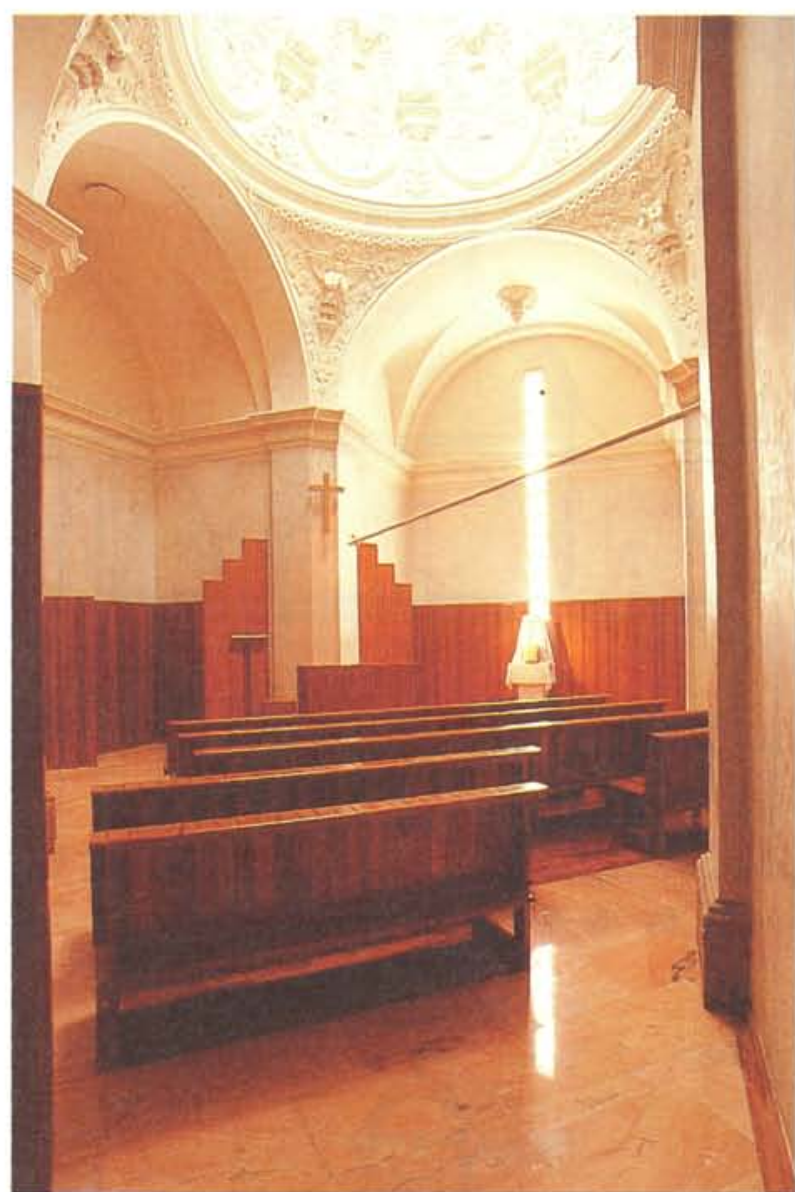

Fig. 18. - Descubrimiento del interior, una vez rebasada la mampara.

Ila. Con esa intención, se los encargamos al escultor barcelonés Joan Mora, de cuyo oficio y poética surgió la peana de mármol blanco en forma de manto, y el "marbrall" (en castellano deberíamos decir, quizás "marmolera"), es decir, una vidriera no hecha de vidrio, sino de finas láminas de mármol. (Figs. 22 y 23).

Volviendo al eje diagonal, los zócalos de madera que protegen los muros, junto a la pilastra central, se tornan rampantes con un perfil quebrado, colaborando en la significación del lugar preferente, el presbiterio. También es ésa una de las funciones de la vara suspendida que, siguiendo ese eje, atraviesa el espacio de pilastra a pilastra (Fig. 24). Con el mismo fin de reforzar el eje diagonal, en la cúpula, frente al altar (Figs. 25 y 26), se pintó un único ángel de color que, además, devuelve a la cúpula la profundidad perdida en parte por su nueva monocromía (1).

(1) Al analizar el concepto de "segunda historicidad" de la Obra de Arte, del que habló Cesare Brandi en su Teoria de la Restauración, se llega a la conclusión - contradictoria con las suyas - de que el monumento es sólo Obra de Arte si es posible transformarlo cuanto sea necesario para mantener el uso y la significación que le unen práctica y emotivamente a la colectividad. $O$ dicho de otro modo: un monumento sólo es Obra de Arte si es reinterpretable por cada generación que lo hereda y se apropia de él, no sólo como espacio útil, sino también como elemento emblemático. Incluso los profesionales que tienen la responsabilidad de oficiar esa apropiación colectiva, tienen la posibilidad de dejar en esos libros "a medio escribir" que son los monumentos, su propio mensaje, mientras no sea distorsionador. El ángel de color de la cúpula de Cardona es fruto de esa posibilidad. 


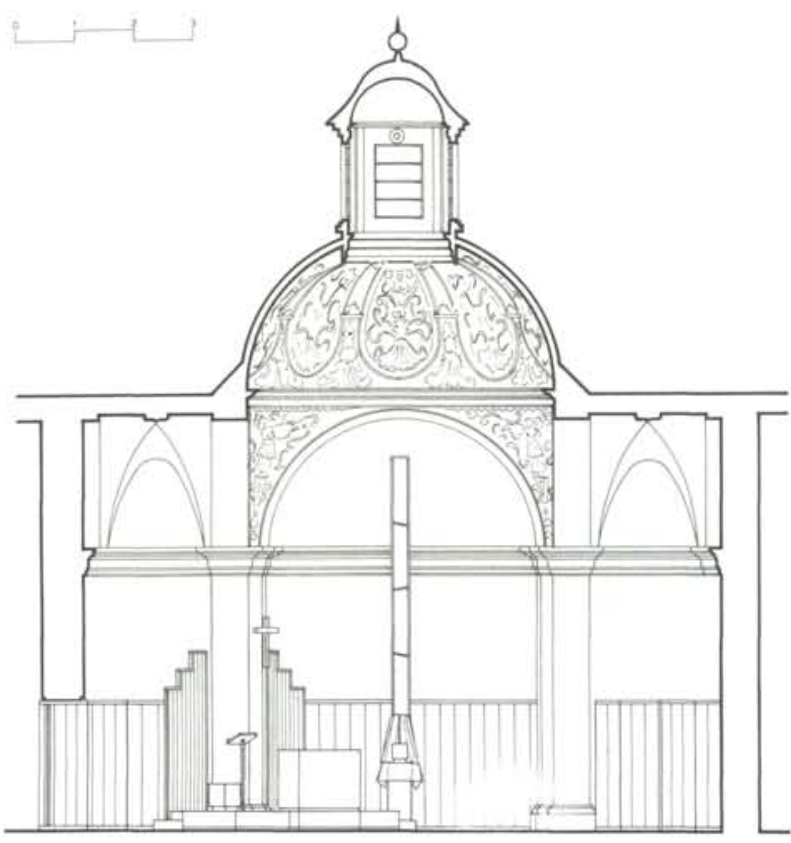

Fig. 19. - Sección transversal por el transepto.

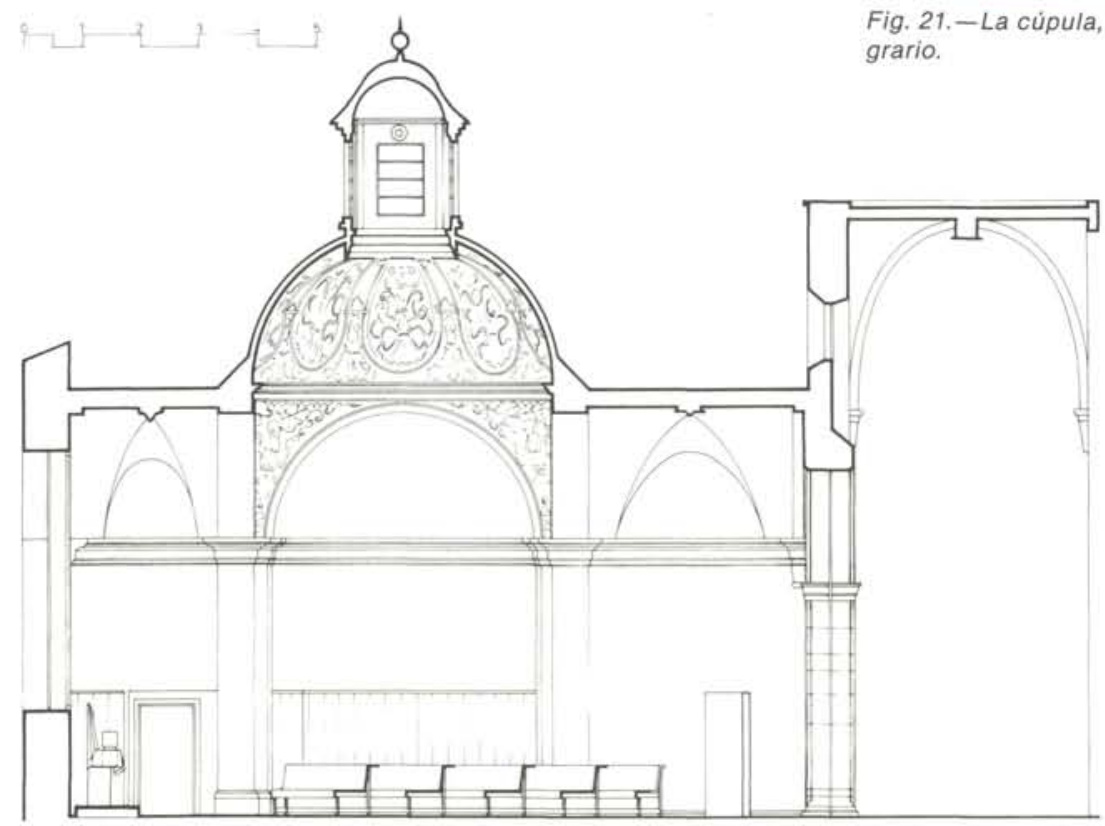

Fig. 19b.-Sección longitudinal por el eje de la nave. grario.

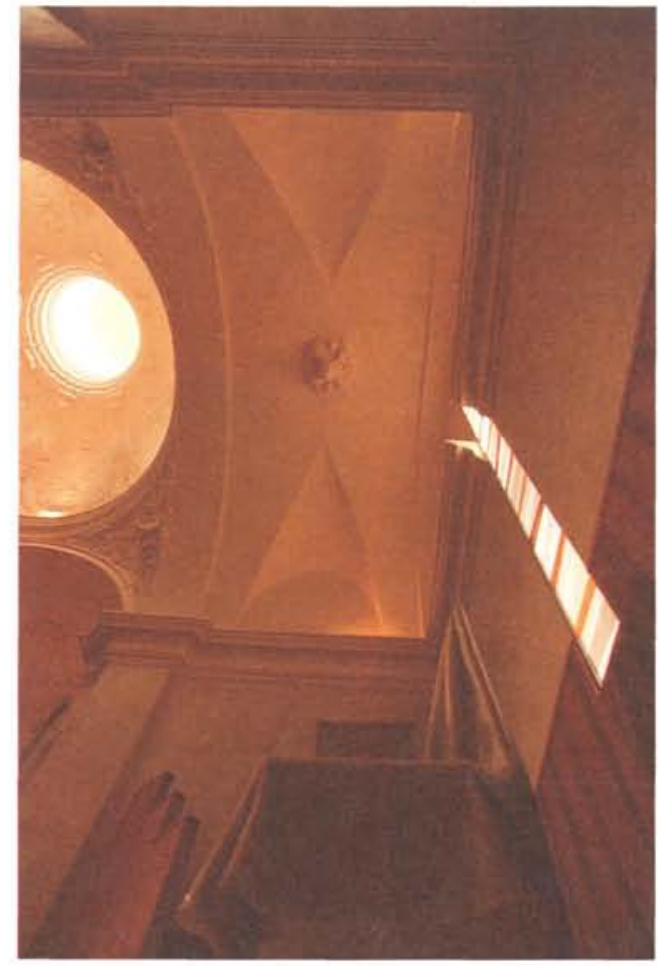

Fig. 21, - La cúpula, el "marbrall", y la peana de mármol con el sa.

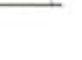

Fig. 20.-Sección perpendicular al nuevo eje 11 . túrgico.

(C) Consejo Superior de Investigaciones Científicas Licencia Creative Commons 3.0 España (by-nc) 


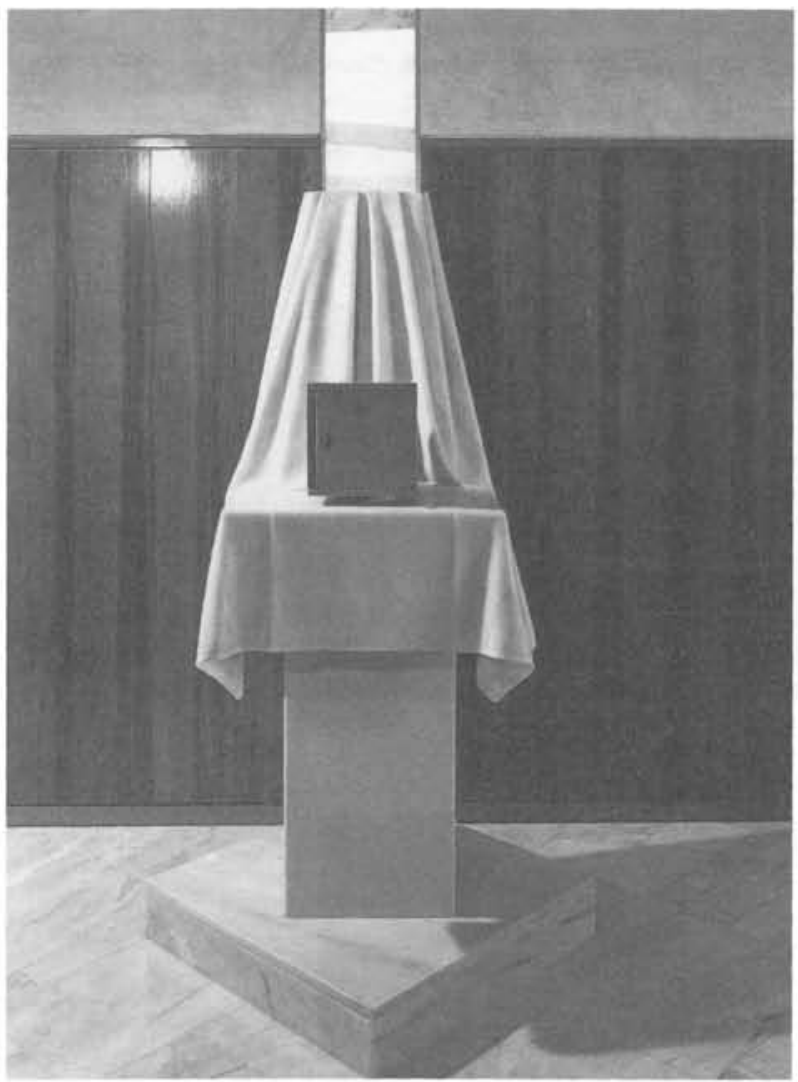

Figs. 22 y 23. - El manto que cubre la peana del sagrario, obra en mármol blanco del escultor Joan Mora.

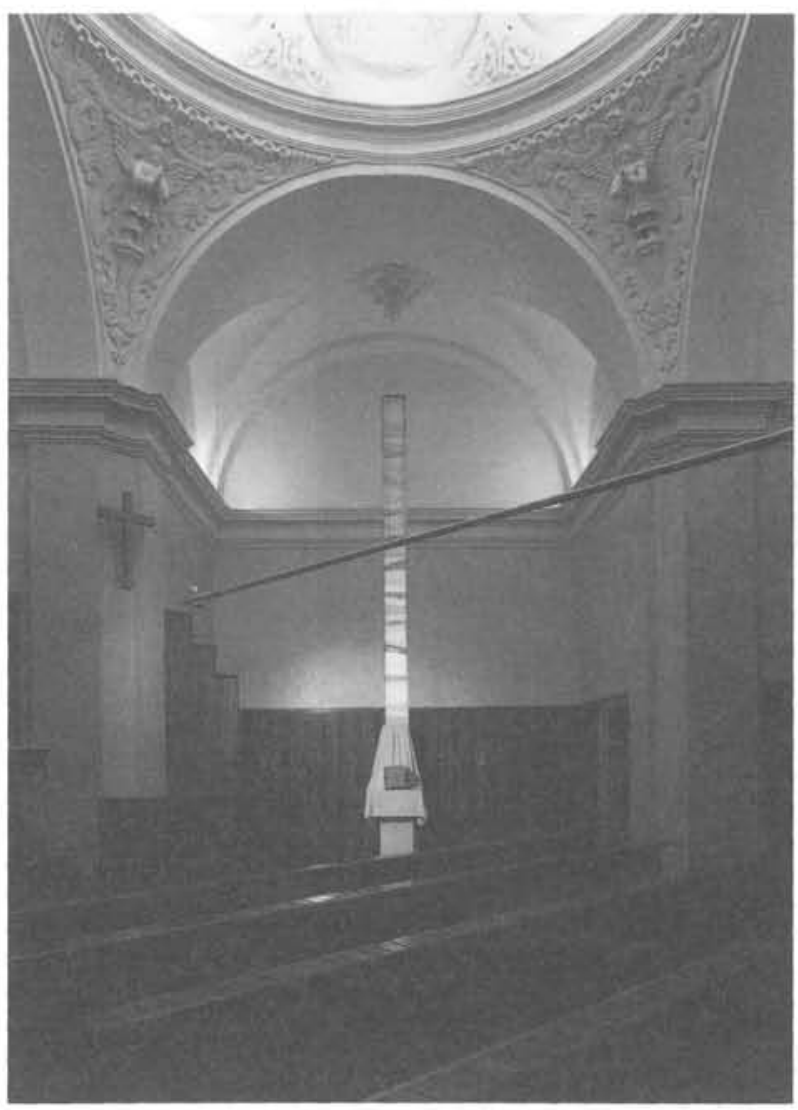

Fig. 24. - La vidriera de mármol que rasga el muro de mediodia.

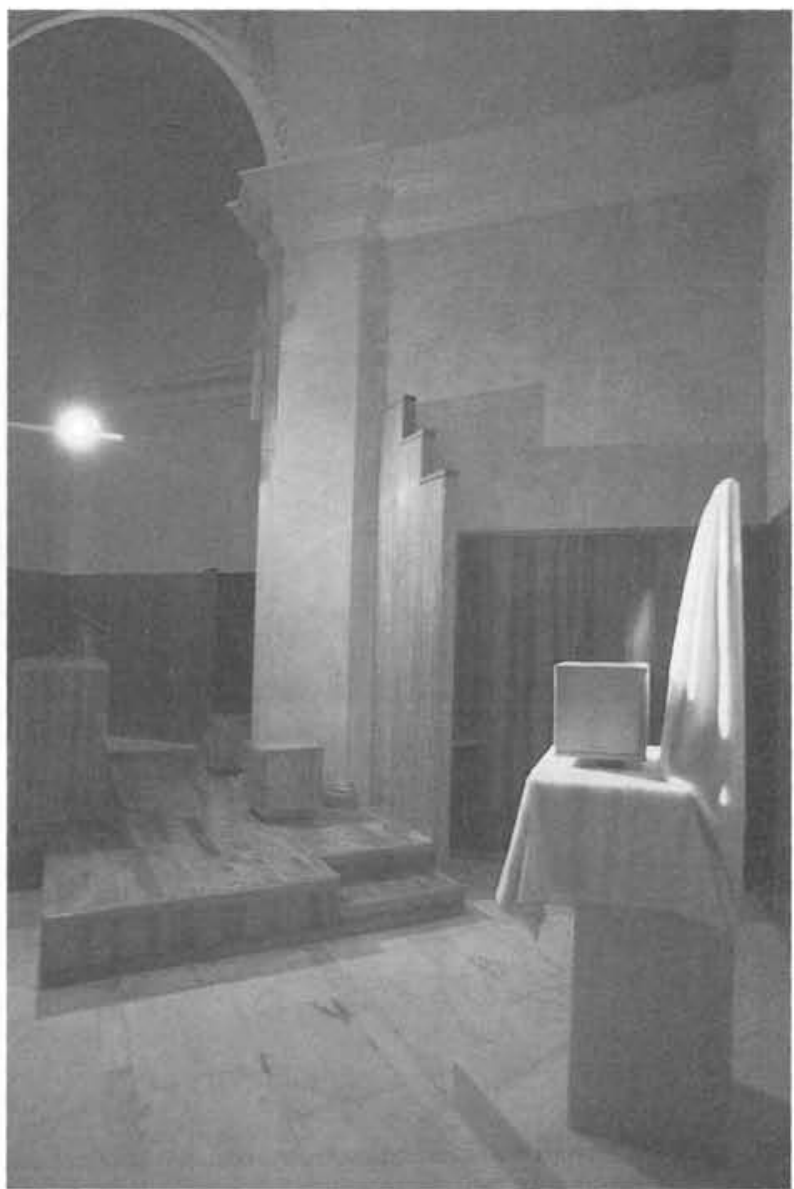

\section{lluminación del espacio}

La pértiga, sin embargo, tiene una función más. La iluminación artificial de la capilla está confiada a luces indirectas discretamente colocadas sobre las cornisas. Un recurso habitual, que aqui resultó eficaz. Esa iluminación, sin embargo, no sirve para los oficios o celebraciones litúrgicas, por su bajo rendimiento puntual que imposibilita la lectura, e incluso por no favorecer ambientalmente el recogimiento propio de los fieles durante esos actos.

Para diseñar el sistema de iluminación, una vez más, recurrimos a imágenes y recuerdos, esta vez de proyectos propios con problemáticas o intenciones similares. En el caso de Santa Candia d'Orpi (Ver Informes n. 397, página 30), el sistema surgió del análisis del uso del templo y de las exigencias de cada tipo de utiliza. ción. La celebración de actos culturales u oficios so. lemnes, o simplemente la contemplación, reclama una iluminación general potenciadora del espacio. Sin embargo, la situación más habitual - pocos feligreses oyendo misa-, pedia una iluminación que ayudara a crear, dentro del espacio general, un "subespacio" vir. tual más proporcionado. Algo así como en las mezquitas, en las que una red de bombillas a pocos metros de altura segrega del gran espacio del templo la zona de oración. 


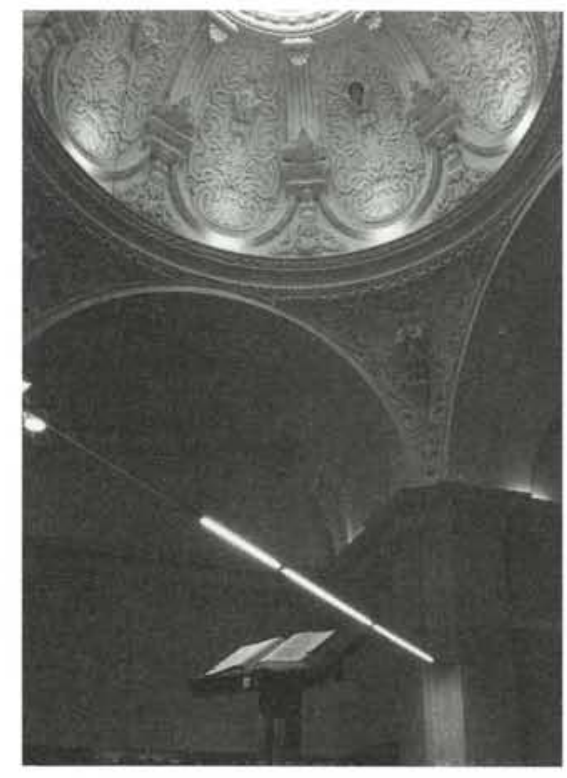

Figs. 25 y 26. - El ángel negro de la cúpula. ("aunque la virgen sea blanca...").
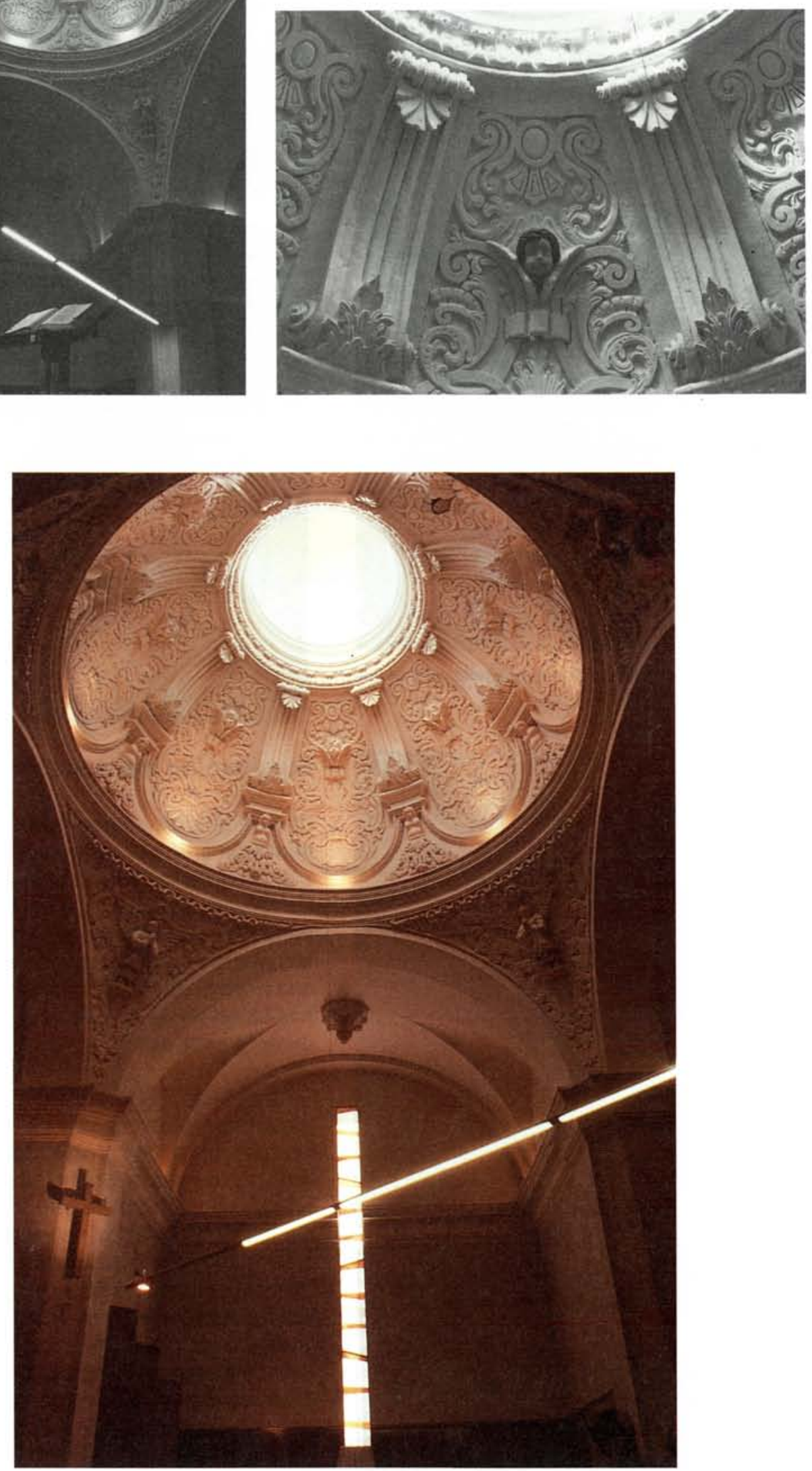

Fig. 27. - La pértiga de luz que marca el nuevo eje litúrgico, y la vidriera de mármol (c) Consejo Superior de Investigaciones Científicas forman una cruz virtual bajo la cúpula. 
En Cardona el problema era similar, asi que repetimos la idea aprovechando la luminaria para remarcar el nue. vo eje litúrgico. El eje de luz horizontal se cruza virtualmente con el "marbrall", cruz aparente que con la linterna dibujan un subliminal juego de simbolismos (Fig. 27). Sobre la luminaria, se sitúan los focos que iluminan el tabernáculo y la sencilla cruz de piedra caliza, obra también del escultor Joan Mora (Fig. 28).

Los tres circuitos que constituyen el sistema general de iluminación (focos de las cornisas, focos puntuales y la pértiga axil) permiten tres posiciones lumínicas distintas según la situación que pueda darse en la capilla. En la situación más frecuente, cuando no se celebran oficios, sólo el tabernáculo es bañado por la luz, mientras de la linterna baja una tenue luz ambiental suficiente para el tránsito y la oración. Esa luz, que sustituye la tradicional lámpara roja, anuncia la presencia de la reserva eucarística. Durante las celebraciones ordinarias (la misa diaria, por ejemplo), la vara central ilumina la asamblea de fieles y da luz al altar y la cruz, mientras las bóvedas y la cúpula parecen desaparecer. En los demás casos (celebraciones extraordinarias, visitas, etc.), todo el sistema de iluminación colabora en la puesta en valor del espacio.

\section{El espacio penitencial}

La mampara del lado del evangelio se abre para permitir el paso a la sacristía, y la del lado de la epistola, que corre por detrás del sagrario, se interrumpe junto a la antigua puerta de acceso a un espacio aparentemente residual que, de acuerdo con el antiguo párroco, y siguiendo también el espíritu del Vaticano II, convertimos en un activo espacio penitencial.

Después del concilio, el sacramento de la penitencia es quizás el que más ha evolucionado en lo formal, hasta llegar a poner en crisis el tradicional confesionario. Mossèn Josep Maria Santcliments, párroco entonces de Cardona, nos pidió que sin desechar la idea de un confesionario a la manera antigua (la feligresía de cierta edad se niega a prescindir de él) dispusiéramos también un espacio donde la confesión pudiera realizarse situándose penitente y confesor a ambos lados de una mesa. Pensando que si los penitentes prefirieran alternativamente uno u otro sistema de confesión, el sacerdote iba a tener que entrar y salir continuamente del despacho, echamos mano una vez más de los re. cuerdos para proyectar una solución.

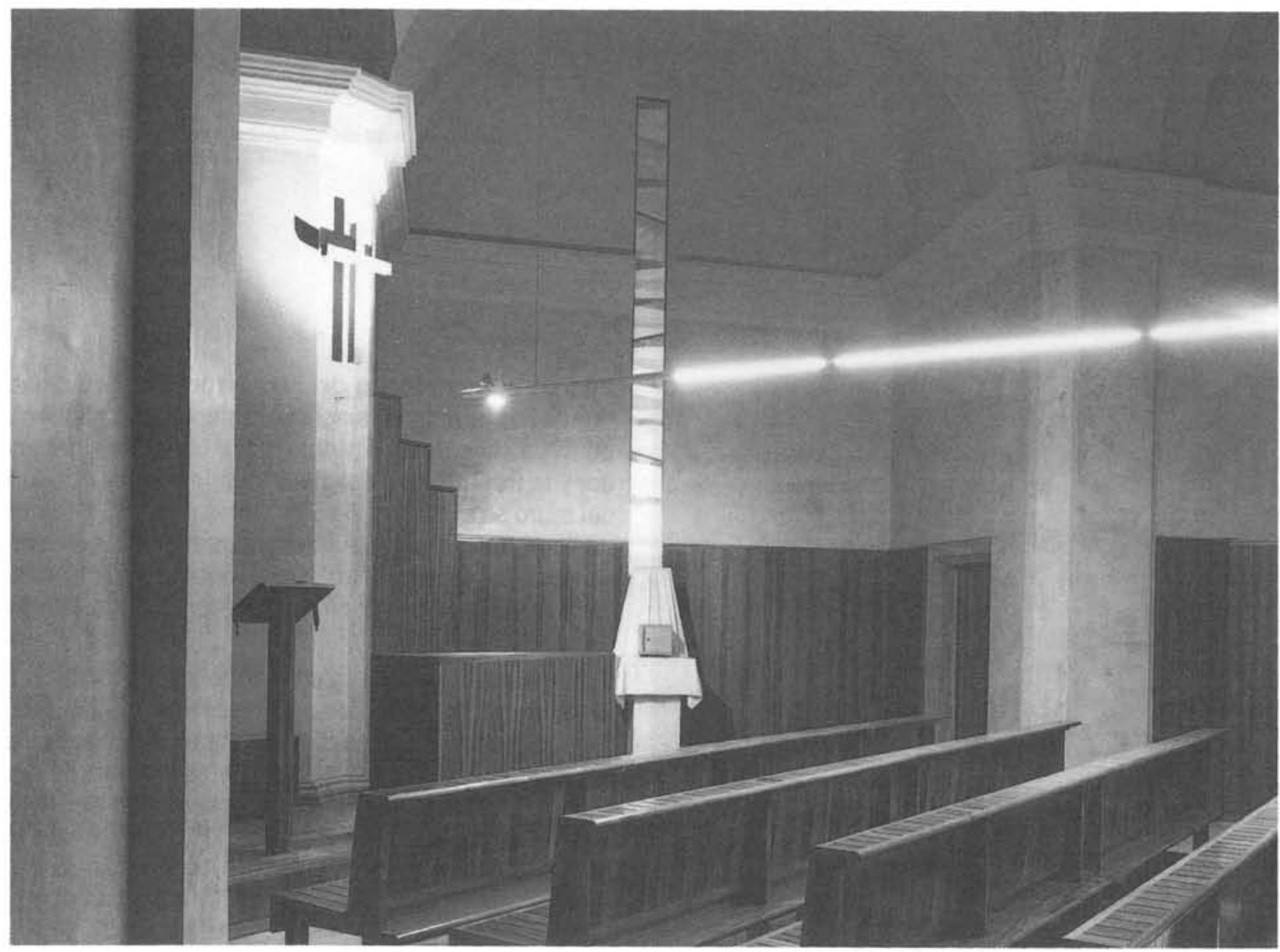

Fig. 28. - lluminación prevista para las celebraciones litúrgicas. 


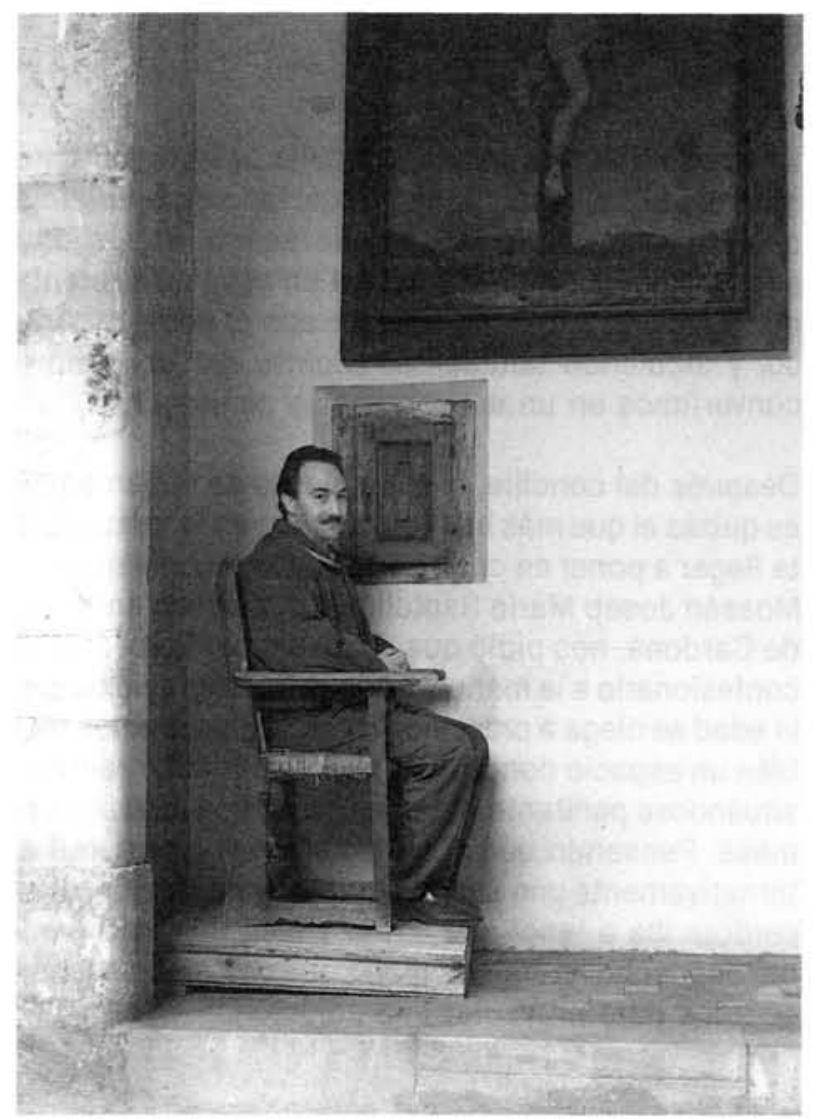

Fig. 29. - El confesionario mural del claustro del monasterio de San Jerónimo, en Granada.

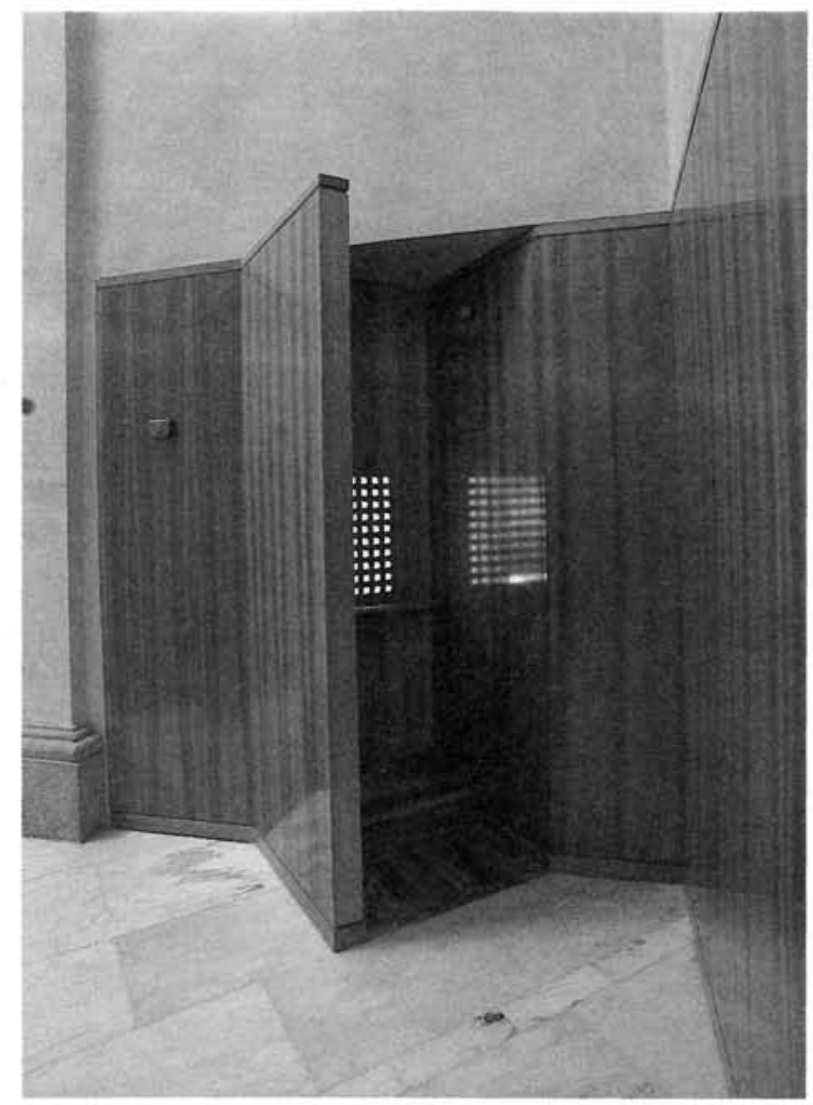

Fig. 30. - El confesionario de la capilla del Santisimo, visto desde el transepto.

(C) Consejo Superior de Investigaciones Científicas Licencia Creative Commons 3.0 España (by-nc)

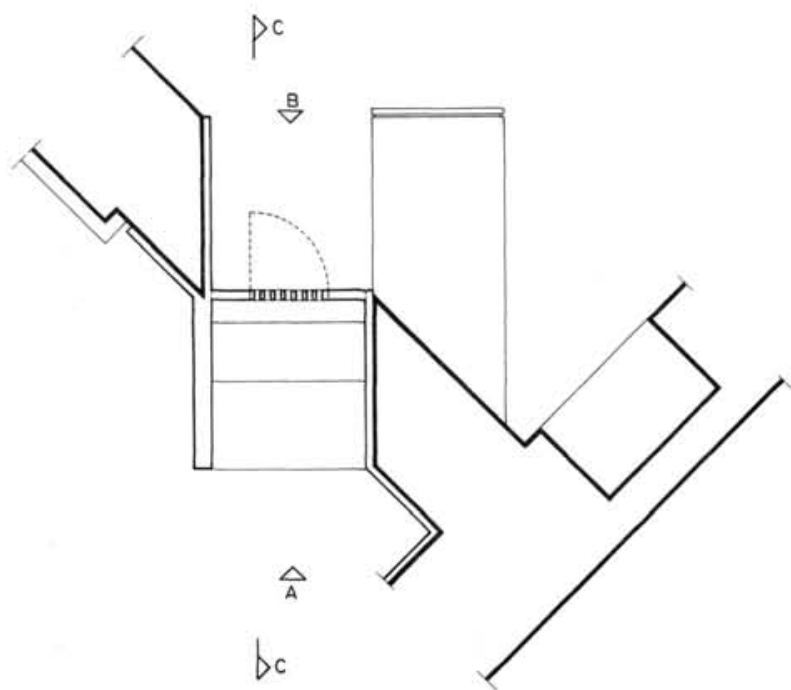

Fig. 31.-Planta del confesionario-despacho.

Fue en el monasterio de San Jerónimo de Granada donde habia visto un singular confesionario mural que permitia al confesor disfrutar, sin interrupción, del frescor y la tranquilidad del claustro mientras al otro lado del muro se sucedian los penitentes (Fig. 29), Y fue así, perforando el muro siguiendo la pauta del pavimento, como se dispuso nuestro confesionario, tradicional hacia la capilla y conciliar hacia el interior (Figs. 30 y 31 ).

Toda la madera utilizada en la obra (en las mamparas, la tarima y los elementos del presbiterio - altar, facistol y banquetas-, el pavimento sobre el que se sitúan los bancos y los propios bancos) es madera de teka con barniz natural a muñeca. El pavimento periférico es de mármol rosa de Portugal, y los muros, hasta las cornisas, fueron estucados en frio, tratándose con pintura al plástico las cornisas, las bóvedas y la cúpula. La calefacción es por suelo radiante (serpentín de agua caliente bajo el pavimento).

http://informesdelaconstruccion.revistas.csic.es 


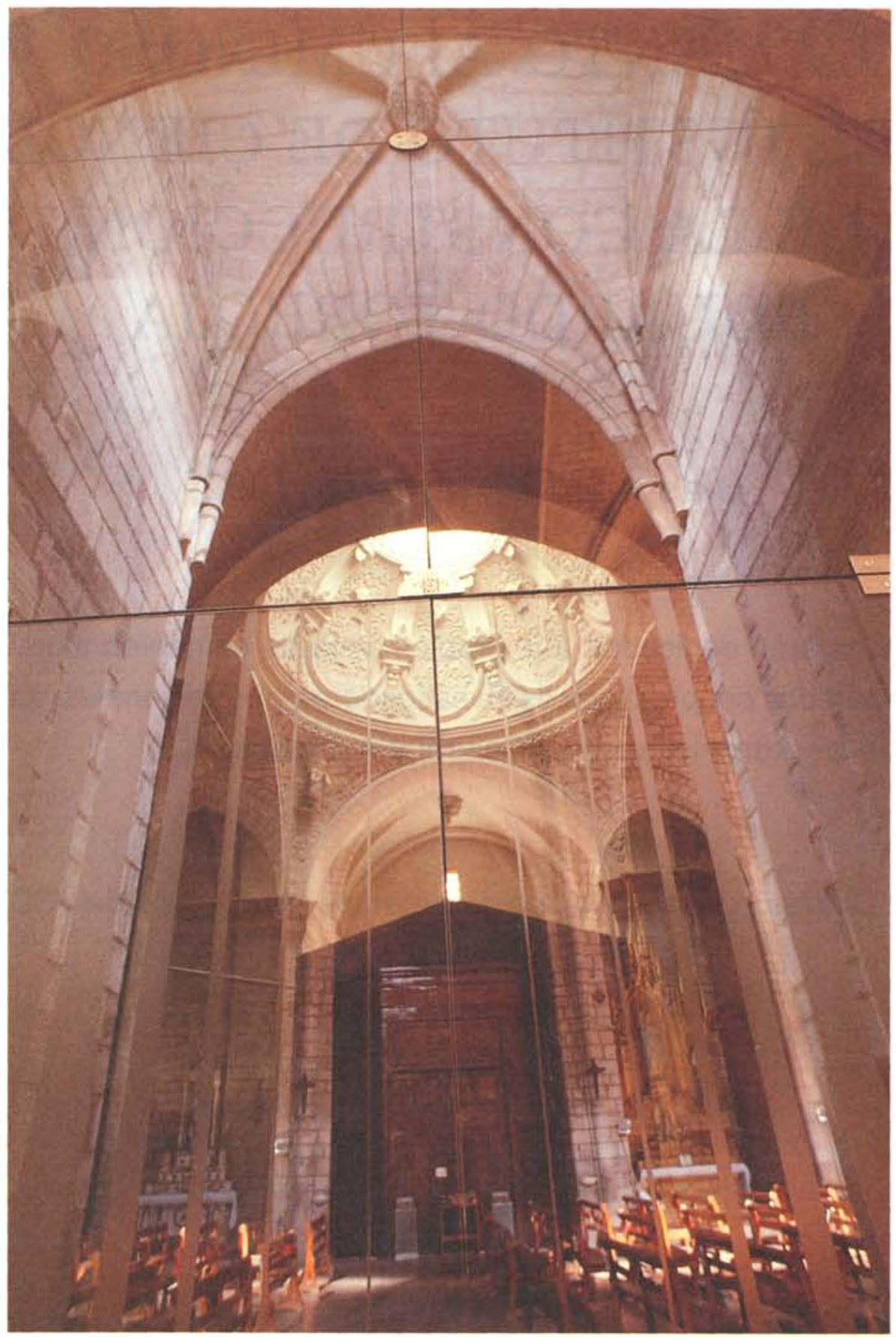

Fig. 32. - Visión virtual de la capilla, desde el interior.

\section{Ficha técnica}

$\begin{array}{ll}\text { Proyecto: } & \text { Diciembre 1990-septiembre } 1991 \\ \text { Obra: } & \text { Marzo-noviembre de 1991 } \\ \text { Fuentes documentales: } & \text { Anna Castellano, Historiadora } \\ \text { Historia del Arte: } & \text { Maria José Sureda, Historiadora } \\ \text { Arqueologia: } & \text { Javier Fierro, A. López Mullor, } \\ & \text { Arqueólogos } \\ \text { Proyecto y dirección: } & \begin{array}{l}\text { Antoni González, Arquitecto } \\ \text { Colaboradores: }\end{array} \\ & \begin{array}{l}\text { Eulália Riera, Xavier Guitart, } \\ \text { Arquitectos }\end{array}\end{array}$

\section{Dirección ejecutiva:}

Maqueta:

Diseño de mobiliario:

Sagrario:

Esculturas:

Constructora:

Coordinador:

Encargado:
Xavier Guitart, Arquitecto; Josefina Gener, Arquitecta Técnica Anna Álvaro

Antoni González, Arquitecto Josep Rovira i Pey, Arquitecto Joan Mora

Urcotex I, S. A. Cardona-Barcelona Josep Maria Sala, Arquitecto

Esteve Mascaró

Fotos: Montserrat Baldomà (Figs. 14, 15, 16, 17, 18, 21, 23, 30 y 32); Joan Francès (Fig. 4); Antoni González (Figs. 1, 17b, 27 y 29); Jordi Isern (cubierta, 22, 24, 25, 26 y 28) y Jaume Soler (Figs. 3 y 9 ) Dibujos: Maite Gómez. 